\title{
LA COMUNIDAD INTERNACIONAL Y LA LUCHA CONTRA LA CORRUPCIÓN EN EL SECTOR PRIVADO
}

\section{Giorgio Cerina}

Dottore magistrale in giurisprudenza, Universita degli Studi di Torino, Italia; Doctor en Aspectos Jurídicos y Económicos de la Corrupción, Universidad de Salamanca, España; Máster en Corrupción y Estado de Derecho, Universidad de Salamanca, España

E-mail: giorgiocerina@usal.es

\begin{abstract}
Resumen
En el siguiente texto se centra el análisis del tema de la corrupción privada y las políticas que han direccionado este fenómeno a partir de la comunidad internacional. La investigación parte del contexto de los últimos sesenta años y se enmarca en el derecho comparado sobre la forma como se ha abordado y desarrollado este flagelo en otros países y hace énfasis en sujetos del sector público y privado. Se plantea el argumento de la proliferación de los instrumentos públicos que combaten el tema de la corrupción, llama la atención el sentido desproporcionado de tales instrumentos y la noción de competencia entre los países que adoptan los mismos, ya que resulta ser un tema politizado se encuentra en ellos más tipos delictivos que requieren la atención del legislador en materia de homogenización, es decir, pasarlos del sector público al campo entre los particulares. Finalmente, se analiza el tema de la corrupción privada desde lo establecido por la Unión Europea, las Naciones Unidas y otros tantos instrumentos jurídicos internacionales que se encargan de demostrar las diferencias, convergencias y contextos sociales para la aplicación en cada país.
\end{abstract}

Palabras Clave: Corrupción privada, Instrumentos Internacionales, Delitos, Tipos Delictivos, Lucha, Tipificar.

\begin{abstract}
The present work focuses on private corruption, and the policies that have been designed by the international community towards this phenomenon. The research starts from the context from the last seventy years, and it checks the way it has been approached and developed on different countries in the public and private sector from a comparative law perspective. The argument about the proliferation of public instruments that counteract corruption is displayed. The disproportion and these instruments calls for attention, and the notion of competencies among countries that adopt these instruments, since this has been a politicized discussion, where it has been found more criminal types of practices that require the attention of the legislator to homogenize the matter, in the sense of, bringing them from the public field to the private area. Finally, the private corruption topic is analyzed from what it has been established by the European Union, United Nations and so many other international juridical instruments that have been in charge of demonstrate the differences, convergences and social contexts to be considered by every country.
\end{abstract}

Key Words: Private corruption, international instruments, offenses, criminal types, typify, counteract private corruption

\section{Résumé}

Dans l'analyse qui suit se concentre la question de la corruption privée et les politiques qui ont abordé ce phénomène de la communauté internationale. L'enquête dans le contexte de ces soixante dernières années et fait partie de droit comparé sur la façon dont a été abordée et développée ce fléau dans d'autres pays et se concentre sur des sujets d'secteurs public et privé. Cela soulève l'argument de la prolifération des instruments publics de combat problème de corruption de, il est frappant de l'effet disproportionné de ces instruments et la notion de concurrence entre les pays qui les adoptent, et qui se trouve être une question est politisée les autres types de criminalité qui nécessitent l'attention du législateur sur l'homogénéisation, c.-à-passe du public au champ entre les individus. Enfin, nous analysons la question de la corruption privée aux dispositions de l'Union européenne, l'Organisation des Nations Unies et de nombreux autres instruments juridiques internationaux qui sont responsables pour démontrer les différences, les convergences et les contextes sociaux pour l'application dans chaque pays.

Mots-clés: Corruption privée, d'instruments internationaux, les crimes, les types de criminels, Combat, sont typiques 

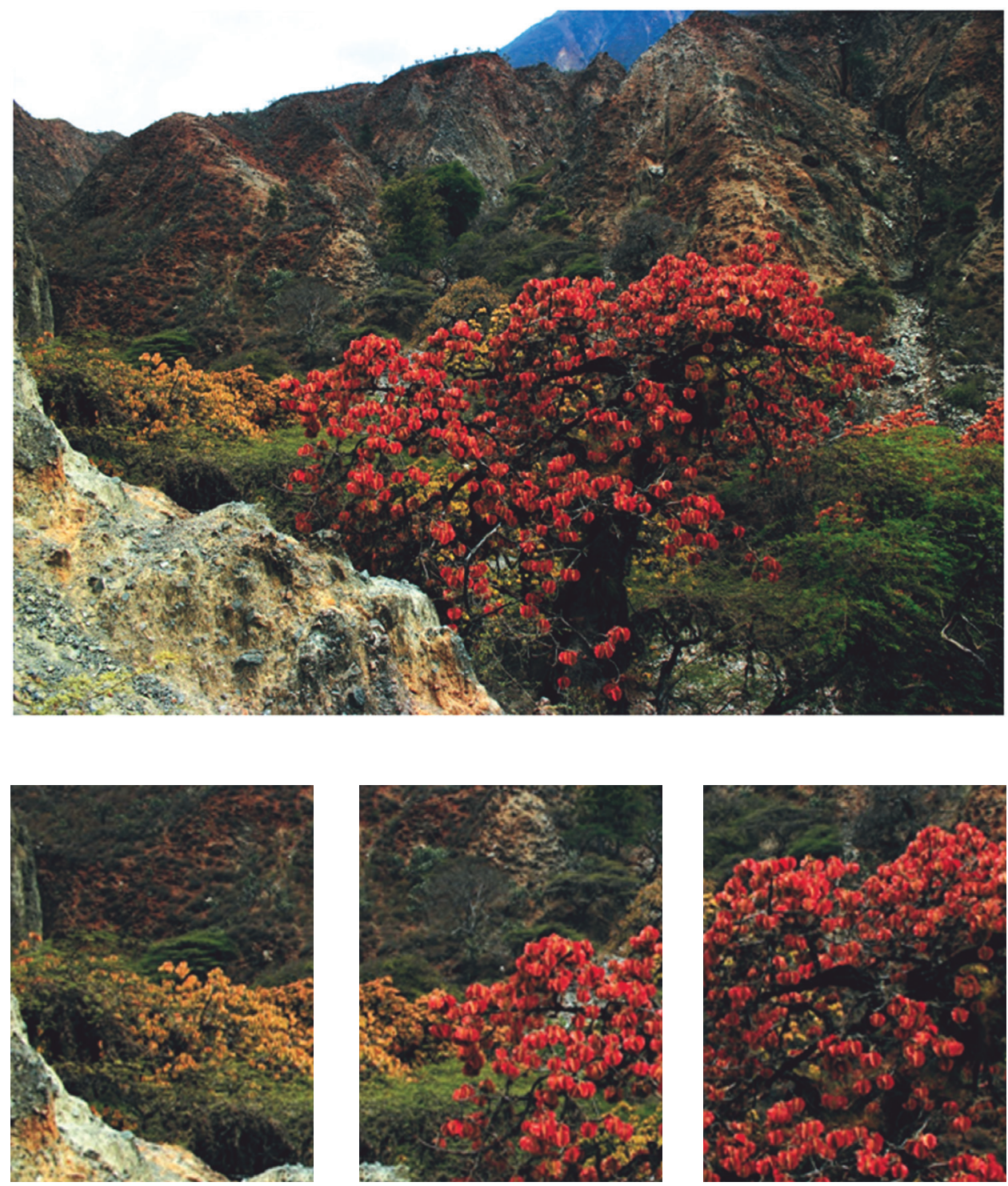

Cañón del Chicamocha - Ceibas Barrigonas

Jorge William Sánchez Latorre 


\section{LA COMUNIDAD INTERNACIONAL Y LA LUCHA CONTRA LA CORRUPCIÓN EN EL SECTOR PRIVADO*}

Giorgio Cerina

\section{INTRODUCCIÓN}

Muy recientemente, en el Código Penal Español, ha hecho su aparición un tipo penal, por lo general, desconocido para los juristas hispano-hablantes. La práctica totalidad de los códigos penales iberoamericanos (incluyendo al portugués y al brasileño), en efecto, ni contemplan normas rubricadas "corrupción entre particulares" ni parecen considerar penalmente ilícitas gran parte de las conductas recientemente tipificadas en el artículo 286 bis del Código Penal Español introducido por la Ley Orgánica 5/2010 (entrada en vigor el pasado día 22 de Diciembre de 2010 después de una vacatio legis de 6 meses $^{1}$ ).

Como se aprehende de una simple lectura de la propia exposición de motivos de la mencionada Ley Orgánica, la introducción de este nuevo delito se apoya en obligaciones contenidas en instrumentos jurídicos internacionales y europeos que, desde hace más de una década, obligan al Reino de España a considerar delictivas las conductas de "corrupción privada". De acuerdo al procedimiento argumentativo sugerido por el propio legislador, por tanto, parece ser que, para entender qué es la corrupción privada y para discutir sobre cómo ha de tipificarse en el código penal dicho ilícito, es indispensable un previo análisis de aquellos instrumentos jurídicos internacionales que obligan o aconsejan su sanción por medio de la extrema ratio del ordenamiento jurídico.

\footnotetext{
* El artículo se enmarca en la Línea Organización y Actividad Empresarial del Grupo Neoconstitucionalismo y Derecho. Facultad de Derecho. Universidad Santo Tomás- Bucaramanga (Col), en el marco del Convenio de Colaboración Conjunta Universidad Santo Tomás - Bucaramanga - Universidad de Salamanca - España

1 Proyecto BOE de 22 de junio de 2010, n.152.
} 
Por otra parte, el estudio resultará relevante también de cara al debate jurídico interno en todos los países que hayan suscrito herramientas jurídicas internacionales que obliguen, por lo menos, a considerar la posibilidad de tipificar como delito el cohecho en el sector privado: entre este grupo de Estados, como veremos en seguida, se encuentra Colombia.

\section{LA GLOBALIZACIÓN DE LA RESPUESTA PENAL FRENTE A LA CORRUPCIÓN. BREVES NOTAS}

El fenómeno de la globalización ${ }^{2}$, con sus ventajas y sus inconvenientes, ha sido difusamente estudiado, no sólo en una óptica económica, sino también jurídica ${ }^{3}$. Limitándonos aquí a algunas consideraciones un tanto superficiales, conviene subrayar que, si globalización significa facilitación del desplazamiento de personas, bienes y servicios, ello implica también facilitación en el desplazamiento de sujetos activos de delitos y de activos necesarios para la comisión de los mismos.

Así como acontece en todos los ilícitos que tienen una importante componente económica, en el caso de la corrupción, es particularmente evidente, por un lado, que

2 Este fenómeno ha encontrado muchas y distintas definiciones. Según Thomas Friedman, por globalización ha de entenderse "la inexorable integración de los mercados, de los Estados-Nación y de las tecnologías a un nivel nunca antes presenciado, de forma que permite a las personas, a las empresas y a los Estados-Nación llegar al mundo más lejos, de forma más rápida, más profunda y más barata que nunca y de manera que permite al mundo llegar más lejos, más rápido, más profunda y más barato que nunca a las personas, a las empresas y a los Estados" Friedman, T., The Lexus and the Olive Tree, 1999 ("inexorable integration of markets, nation-states and technologies to a degree never witnessed before-in a way that is enabling individuals, corporations and nation-states to reach round the world farther, faster, deeper and cheaper than ever before"). La definición es la citada por Fabián Caparrós, E.A., La corrupción de agente público extranjero e internacional, Ratio Legis, Salamanca, 2002, p. 29. El premio Nobel por la economía Joseph Stiglitz ha hablado de la globalización como de "the closer integration of the countries and peoples of the world (...) brought about by the enormous reduction of costs of transportation and communication, and the breaking down of artificial barriers to the flows of goods, services, capital, knowledge, and people across borders" o, en la traducción española, como de "la supresión de las barreras al libre comercio y la mayor integración de las políticas nacionales" (Stiglitz, J. E., El malestar de la globalización, Taurus, Madrid, 2003, p. 11). Para una conceptualización de la globalización relacionada con el derecho penal, véase Quintero Olivares, G., "El Derecho Penal ante la globalización", en AA.VV., Zúñiga Rodríguez, L. -Méndez Rodríguez, C. -Diego Díaz-Santos, M. R. El Derecho Penal ante la Globalización, Colex, Madrid, 2002, pp. 11 y ss.

3 Parece absolutamente pacífica la afirmación de Silva Sánchez, J. M., La expansión del Derecho penal, Julio César Faira, Montevideo, Buenos Aires, 2006, p. 119 que observa que "la globalización política y cultural provoca (...) una tendencia hacia la universalización del Derecho, también del Derecho penal". 
la integración de los mercados facilita que corruptos y corruptores puedan concluir sus negocios al operar en distintos países ${ }^{4} \mathrm{y}$, por otro, que será, cada vez, menos engorroso para los sujetos activos elegir el foro jurídico (penal) más conveniente para realizar sus actividades ilícitas (léase, con legislación penal menos desfavorable) ${ }^{5}$. Al primer aspecto (iter criminis que tiene lugar en distintos Estados), se le suele rotular como transnacionalización de la actividad delictiva mientras que la doctrina se refiere normalmente al segundo (elección del foro más favorable) como jurisdiction shopping ${ }^{6}$

Ambos fenómenos (rectius, modi operandi) se han insertado sobre un contexto

4 A este respecto, el I considerando de la Decisión Marco sobre corrupción en el sector privado (de la que se dirá en seguida), recuerda que "Junto con la mundialización, los últimos años han traído un aumento del comercio transfronterizo de bienes y servicios, por lo que la corrupción en el sector privado de un Estado miembro ha dejado de ser un problema meramente interno para convertirse en un problema también transnacional, que se aborda más eficazmente mediante una actuación conjunta de la Unión Europea”.

5 Véanse, sobre este punto, las consideraciones de Rodríguez García, N., "La necesaria flexibilización del concepto de soberanía en pro del control judicial de la corrupción”, en Rodríguez García, N. -Fabián Caparrós, E. A. (Coords.), La corrupción en un mundo globalizado: análisis interdisciplinar, Ratio Legis, Salamanca, 2004, p. 242. Afirma el autor que el fenómeno de la corrupción, "sin duda, está íntimamente relacionado y favorecido por la globalización de las relaciones, fundamentalmente las de naturaleza económica". Véanse también Silva Sánchez, J., La expansión(...)cit., p. 91 en donde el autor observa que "desde el punto de vista material, la criminalidad de la globalización es criminalidad de sujetos poderosos, caracterizada por la magnitud de sus efectos, normalmente económicos, pero también políticos y sociales. Su capacidad de desestabilización general de los mercados así como de corrupción de funcionarios y gobernantes, son rasgos asimismo notables". Sobre la internacionalización de la corrupción, entre muchos, véanse también Mueller G. O. W., "Transnational Crime: Definitions and Concepts", en Williams P. -Vlassis D., Combating Transnational Crime: Concepts, Activities, and Responses, Routledge, 2001, p.15; Cotler, I., "Globalization, Human Security, and the Role of International Criminal Law", en AA.VV., The Changing Face of International Criminal Law. Selected Papers, Canadian Department of Justice, 2002, p. 24; Huber, B., "LA lucha contra la corrupción desde una perspectiva supranacional", en Revista Penal, 2003, Vol. II, pp. 41 y ss.

6 Observa Baumann que "Existe una enorme ventaja de la que goza la nueva élite de la globalización cuando se encuentra frente a los guardianes del orden: el orden es local, mientras que la élite y las reglas del libre mercado sobre las cuales ella se apoya son trans-locales. Si los guardianes del orden local son demasiados invasivos o molestos, si la situación se hace demasiado incómoda, existe siempre la posibilidad de desplazarse a otro siti o: globalidad de la élite significa siempre movilidad y movilidad quiere decir posibilidad de escapar, de evadir. Existe siempre algún lugar en el cual el orden local no choca con los usos del mercado global, o en donde los guardianes locales son felices y dispuestos a mirar para otra parte cuando dicho choque se produce. Todos estos factores considerados unitariamente convergen hacia un efecto común: la identificación del crimen con la (siempre localizada) "clase inferior", es decir, de forma absolutamente equivalente, la criminalización de la pobreza" (Bauman, Z., "Social Issues of Law and Order", en The British Journal of Criminology, n. 40, 2000, p. 219). 
jurídico-penal, por lo general, inadecuado para hacerles frente ${ }^{7}$ : el tradicional límite al ius puniendi fijado por la territorialidad -profundamente conexo con una idea de la sanción penal como expresión directa de la soberanía nacional-, por un lado (como regla general), dificulta la investigación y persecución de delitos más allá de los confines nacionales y, por otro, está a la base del persistir de diferencias sustantivas en las legislaciones estatales cuyos autores parecen guiados por el exclusivo interés de los ciudadanos-electores residentes en el país- o, en algunos casos, en el suyo propio-.

Por otra parte, en el último cuarto del siglo pasado, el florecer de estudios -y también de escándalos-relacionados con el tópico "corrupción del funcionario público" ha puesto de manifiesto que los efectos negativos de este fenómeno van más allá de los confines nacionales y que los supuestos de cohecho transnacional ${ }^{8}$ pueden impactar profundamente sobre la opinión pública de un país. Ello ha acentuado la necesidad de poner remedio a los inconvenientes antes mencionados y relacionados con una concepción Estado-céntrica del derecho penal: la toma de conciencia de que quien corrompe termina por condicionar negativamente el desarrollo socioeconómico del país en el que opera el corrompido9 ${ }^{9}$, la presión de algunos Estados pioneros en adoptar medidas para la sanción del cohecho transnacional y el fin de la guerra fría, entre otros factores, han hecho posible que la comunidad internacional centrara sus esfuerzos en elaborar una serie de herramientas cuyas finalidades esenciales pueden reducirse esquemáticamente a dos: armonización $^{10}$ de las distintas legislaciones

7 "La indiscutible tendencia de la época a la unidad global impone el silencio a los juristas, como una vez lo impuso a los teólogos y condena el poder jurisdiccional al "ocasionalismo", también porque le quita aquel territorio cierto y definido que es el texto de la ley y su legíbilidad, sujeto inexorablemente al único lenguaje que parece haber sobrevivido: aquel de la "libertad" del comercio, de la economía y de la técnica universales" (FORTI, G., "Il volto di Medusa: la tangente come prezzo della paura”, en Forti, G., (DIR.) Il prezzo della tangente, Vita e Pensiero, Milano, 2003, p. XXII).

8 Conviene mantener distintos el cohecho transnacional y el cohecho del funcionario público extranjero, entendiendo el segundo como species del primero. Como crimen transnacional, en general, se hace referencia a aquellos delitos que se desarrollan en dos o más países distintos. Es evidente, por tanto, que incluso el cohecho del funcionario público nacional puede presentarse como crimen transnacional (piénsese, por ejemplo, al supuesto en el cual un empresario español utiliza un intermediario suizo y, a través de una cuenta sita en este último país, decide corromper a un funcionario público español que presta sus servicios en la Administración pública española).

9 Sobre este punto, véanse las consideraciones de Fabián Caparros, E. A., La corrupción...cit., pp. 32 y ss.

10 Entorno al concepto de "armonización", véase Vogel, J., "Estado y tendencias de la armonización del Derecho penal material en la Unión Europea”, en Revista Penal, 2002, pp. 112 y ss. Como puede y podrá observarse en las páginas siguientes se adopta en este trabajo un concepto amplio y posiblemente a-técnico de "armonización". Ello incluye seguramente a la "asimilación" y a la “estandarización o unificación”. Sobre la diferencia entre unificación, armonización e integración, véase Delmas-Marty, M., "Objetivos y metodología”, en AA. VV., Delmas Marty, M. -Pieth, M. -Sieber, U. (DIRS.), Los Caminos de la armonización penal, Tirant lo blanch, Valencia, 2009, pp. 28 y ss. 
nacionales en materia de corrupción y adopción de mecanismos que incentiven la cooperación entre Estados.

En particular, a mediados de los 70, el legislador de los Estados Unidos, empujado por una opinión pública sacudida por el escándalo relacionado con el pago de sobornos a funcionarios extranjeros por parte de la empresa fabricante de aviones Lookheed, decidió dotarse de una severa normativa que sancionara duramente senda práctica (el Foreign Corrupt Practices Act de 1977¹'). En aquel momento, sin embargo, el derecho comparado ofrecía numerosos ejemplos de legislaciones que parecían valorar positivamente que una empresa nacional utilizara la corrupción del extranjero como medida comercial (previéndose, en numerosos casos, la posibilidad de deducir de los impuestos los costes soportados). Ello, evidentemente, terminó por situar a las empresas norteamericanas en una situación de clara desventaja comercial respecto de sus competidoras con sede en el extranjero que contaban con una formidable herramienta comercial cuya utilización había quedado prohibida en EEUU ${ }^{12}$. De ahí la, cada vez, mayor presión de este país sobre las principales organizaciones internacionales para que promovieran la adopción, en otros países, de medidas parecidas a las incorporadas en el $F C P A^{13}$.

Probablemente debido, entre otras cosas, al perdurar de la guerra fría, hubo que esperar a la segunda mitad de los 90 del siglo pasado para que dicha presión surtiera sus efectos. ${ }^{14} \mathrm{Y}$ es significativo que el primer convenio internacional anticorrupción (la

11 Sobre este punto, véase Fabián Caparrós, E. A., La corrupción(...)cit., pp. 30 y ss. y la bibliografía que ahí se menciona. Véase también, entre otros, ACQUAVIVA, G., "La legislazione statunitense in materia di lotta alla corruzione di fronte agli ultimi sviluppi internazionali", en Rivista del Commercio Internazionale, n. 3, 2001, pp. 625 y ss.; Sobre la importancia del Act de cara al futuro desarrollo de la armonización de las legislaciones penales en materia de corrupción, véase también Tiedmann, K., "Frode, corruzione e armonizzazione giuridica in Europa”, en Rivista Trimestrale del Diritto Penale dell'Economia, n. 1-2, 2007, p. 94.

12 Véase, una vez más, Fabián Caparrós, E. A., La corrupción...cit., pp. 41 y ss.

13 A este respecto, recuérdese que el primer Convenio enteramente dedicado a la penalización del Cohecho del funcionario público extranjero se adoptó en el marco de la OCDE, organización internacional que agrupa a los mayores países exportadores.

14 Véase, sobre este punto, Nieto Martín, A., “AAmericanización o europeización del Derecho penal económico?”, en AA. VV., Delmas-Marty, M. -Pieth, M. -Sieber, U. (DIRS.), Los Caminos de la armonización penal, Tirant lo blanch, Valencia, 2009, pp. 435 y ss.; Pieth, M., "La armonización del Derecho penal: la prevención de la corrupción como caso de estudio", en AA. VV., DelmasMarty, M. -Pieth, M. -Sieber, U. (DIRS.), Los Caminos de la armonización penal, Tirant lo blanch, Valencia, 2009, pp. 296-298, 321 y ss.; Según observa Bautista, O. D., ("Marco institucional para establecer un dique internacional a la corrupción", en Cuadernos de derecho público, No. 29, 2006, p. 142) un cambio radical de perspectiva es de colocarse a principios de los años 90: el autor hace referencia a la operación manos limpias que empezó en Italia en 1992, a la creación, en 1994 del Grupo Multidisciplinario sobre la corrupción dentro de la Dirección de Asuntos Jurídicos del Consejo de Europa; en el mismo año, la OCDE creaba el Grupo de trabajo sobre cohecho en las operaciones comerciales internacionales; en el 1995, la OCDE organizaba el Simposio sobre corrupción y prácticas sanas de Administración que tuvo lugar en aquel mismo año en París; en 
Convención Interamericana contra la Corrupción abierta a las firmas en el año 1996) dedicara un precepto a la penalización de la corrupción del funcionarios públicos extranjeros ${ }^{15}$, tópico al cual sería enteramente adscrita la siguiente Convención de la OCDE del año 1997.

\section{LA PROLIFERACIÓN DE LOS INSTRUMENTOS INTERNACIONALES DE LUCHA CONTRA LA CORRUPCIÓN Y LA PROLIFERACIÓN DE LOS TIPOS DELICTIVOS EN ELLOS CONTENIDOS}

Si, desde el Foreign Corrupt Practice Act hasta la abertura a las firmas del primer convenio internacional de lucha contra la corrupción transcurrieron cuatro lustros, en los 7 años siguientes a la adopción de la Convención Interamericana contra la Corrupción, los instrumentos jurídicos internacionales con disposiciones relevantes en la materia elaborados en el marco de diversas otras organizaciones internacionales han sido ocho ${ }^{16}$ (¡más de uno por año!). Hoy en día, la Organización de Estados Americanos cuenta con un instrumento (la ya mencionada Convención Interamericana contra la Corrupción); la OCDE también con uno (la Convención para combatir el cohecho de servidores públicos extranjeros en transacciones comerciales internacionales de 1997); la Unión Europea con dos (el primer protocolo anexo al Convenio para la protección de los intereses financieros de la Comunidad Europea de 1996 y el Convenio relativo a la lucha contra los actos de corrupción en los que estén implicados funcionarios de las Comunidades Europeas o de los Estados miembros de la Unión Europea de 1997); el Consejo de Europa con dos (las convenciones de derecho civil y de derecho penal de lucha contra la corrupción, respectivamente, de 1999 y de 1998 ); las Naciones Unidas con dos (la Convención contra la Delincuencia Organizada Transnacional ${ }^{17}$ del año 2000 y la Convención contra la Corrupción del año 2003); la Unión Africana con uno (la Convención para prevenir y combatir la Corrupción del año 2003). Ello, sin mencionar recomendaciones, directrices, y otras herramientas jurídicas adoptadas en el marco de los tratados constitutivos de la Unión Europea.

1996 el presidente del Banco Mundial anunció una serie de Medidas para combatir la corrupción. En ese mismo año la OEA organizaba en Caracas la Conferencia especial para adoptar una Convención interamericana contra la corrupción(...) En verdad pretender listar a todas las iniciativas es tarea demasiado compleja para el autor de este trabajo. Baste con observar el aumento de la actividad internacional anticorrupción en la década de los ' 90.

15 Sobre el punto, véase Manfroni, C. A., Soborno Transnacional, Abeledo-Perrot, Buenos Aires, 1998, passim y, en particular, pp. 74 y ss.

16 Y no seis como parece sugerir la página Web de la Interpol que, curiosamente, no menciona los convenios europeos (véase http://www.interpol.int/Public/Corruption/Conventions/defaultES.asp).

17 Que, en su artículo 8, promueve la tipificación del delito de cohecho. 
Este proliferar de instrumentos jurídicos debe ciertamente llamar la atención. Más que a una necesidad imperante de combatir el fenómeno "corrupción" -necesidad que bien podría haberse satisfecho con dos o tres instrumentos jurídicos internacionales adoptados a escala regional o bien con un único convenio elaborado en el marco de las Naciones Unidas-y más que la idea de complementar o perfeccionar instrumentos anteriores- planteamiento que podría haberse llevado a cabo al sustituir y no yustaponer nuevas herramientas-, parece haber jugado cierto papel lo ha sido definido como populismo sancionador ${ }^{18}$ : ansiosos de encontrar el consenso de la opinión pública, tanto las diversas organizaciones internacionales como sus Estados miembros parecen haberse involucrado en una especie de competición para elaborar, promover, ratificar el mayor número de instrumentos jurídicos posibles en el tópico "lucha contra la corrupción". Resultado de la consiguiente hipertrofía legislativa internacional es un panorama normativo innecesariamente complejo, a veces, contradictorio y, por lo general, ineficaz (vista la dificultad a la hora de elaborar instrumentos de seguimiento de la implementación de los instrumentos jurídicos internacionales).

Amén del progresivo aumento del número de convenios internacionales existentes en la materia, debe también llamar la atención la cada vez mayor extensión de los mismos: dejando a un lado las herramientas jurídicas no enteramente dedicadas a la corrupción (como la Convención de las Naciones Unidas contra la Delincuencia Organizada Transnacional) o que se centran en un tipo específico de corrupción (como la Convención de la OCDE del año 1997), es llamativo que, desde los 28 artículos que componen la Convención Interamericana contra la Corrupción del año 1996, se haya pasado a los 71 de la Convención de las Naciones Unidas contra la Corrupción del año 2003. Y, si limitamos la comparación a aquellos preceptos relacionados con la tipificación de delitos (y, por ende, con la armonización de las legislaciones penales sustantivas de los países miembros), podemos observar que los artículos dedicados a la criminalización de conductas presentes en la Convención de las Naciones Unidas contra la Corrupción superan por más de tres veces los contenidos en la Convención Interamericana contra la Corrupción.

Más allá de observaciones inherentes al principio de subsidiariedad o a la falta de legitimidad democrática del legislador internacional para intervenir tan masivamente en la materia penal ${ }^{19}$, y al margen -de momento- de toda consideración acerca de la

18 Sobre la utilización de esta expresión, me limito aquí a remitir a Roberts, J. V. -Stalans, L. J. -Indermaur, D. Hough, M., Penal Populism and Public Opinion, Oxford University Press, USA, 2002; Pratt, J., Penal populism, Routledge, 2007.

19 Sobre este punto, entre otras, véanse, las consideraciones de Silva Sánchez, J., La expansión...cit., p. 94; Nieto Martín, A., "Posibilidades y límites de la armonización del Derecho Penal nacional tras Comisión v. Consejo (comentario a la STJCE, asunto C-176/03, de 13-9-2005)”, en Revista española de derecho europeo, n. 17, 2006, p. 198 y ss; Grasso, G., "La formación de un Derecho penal de la Unión Europea,” en Revista del poder judicial, n. 52, 1998, p. 179. 
compatibilidad entre los preceptos que se obliga a incluir en los códigos penales y los principios básicos del derecho penal en el Estado de Derecho contemporáneo (entre todos, el de lesividad) ${ }^{20}$, la anterior observación permite ahora subrayar dos características generales de la armonización de las distintas normativas nacionales en materia de corrupción.

En primer lugar, cuando se habla de armonización, se significa siempre tipificación por parte de algunos países de conductas antes penalmente irrelevantes y nunca obligación de considerar lícito un supuesto antes delictivo: el legislador internacional se limita a establecer un estándar mínimo de conductas penalmente relevantes, es decir, fija límites por debajo pero nunca por arriba. En materia de corrupción, en otras palabras, los convenios internacionales obligan siempre a ampliar el abanico de conductas a considerarse delictivas a incluirse en el Código Penal Estatal de los países miembros.

En segundo lugar, conviene poner en relación la anterior consideración con el procedimiento mediante el cual se redactan las normas internacionales. En este marco, el derecho interno no parece ser sólo el punto de llegada de los tratados internacionales, sino que es inevitablemente también su punto de partida. Al igual que en materia de corrupción del funcionario público extranjero ${ }^{21}$, en efecto, es relativamente intuitivo argumentar que, a la hora de negociar la inclusión en el texto de un tratado de la obligación de tipificar uno o más delitos, las delegaciones de los Estados traten que el texto definitivo del convenio se asemeje lo más posible al derecho vigente en su propio país.

La actitud parece, en parte, comprensible. Ya se ha dicho a propósito de la corrupción del funcionario público extranjero: la prohibición unilateral por parte de un Estado de senda práctica termina por privar a los agentes económicos que operan en su territorio nacional de una posible herramienta comercial. Ahora, si dicha herramienta es aún lícita en otros contextos nacionales, resulta evidente la desventaja competitiva de aquellos agentes que operan en el contexto normativo menos favorable. De ahí, el interés del país pionero en sancionar en que todos los demás también prohíban, interés que generalmente resulta contrapuesto respecto al de aquellos que, al sancionar, pierden la mencionada ventaja competitiva. Los gobiernos de estos últimos países tenderán a oponerse a la nueva tipificación en tanto en cuanto la defensa de la impunidad les resulte rentable frente a la opinión de sus electores y de la comunidad internacional. Las organizaciones internacionales, por su parte, tratarán de promover la adopción de herramientas jurídicas susceptibles de ser ratificadas por el mayor número de países miembros, al tratar así de mediar entre los distintos intereses contrapuestos.

20 Véase, Nieto Martín, A., "La armonización del derecho penal ante el tratado de Lisboa y el programa de Estocolmo", en Revista General de Derecho Penal, n. 13, 2010, pp.. 2 y ss. (versión electrónica).

21 Véase supra 
Ahora bien, si es relativamente sencillo intuir las mecánicas subyacentes a la progresiva incorporación a los tratados internacionales de la corrupción del funcionario público transnacional ${ }^{22}$, manténgase que algo parecido puede ocurrir con toda una serie de otros tipos delictivos que pueden resultar nuevos para buena parte de los legisladores hispano-hablantes pero que son bien conocidos y arraigados en contextos jurídicos de nuestro entorno muy cercano: entre ellos, se encuentra la corrupción entre particulares.

Como veremos con mayor detenimiento más adelante, la utilización de la rúbrica "corrupción" para rotular conductas que nada tienen que ver con el funcionamiento de la Administración pública resulta heterodoxa en un contexto jurídico como el español o el italiano (exceptuado, por obvias razones, el delito de corrupción de menores que ahora no viene a cuento). Al contrario, si dirigimos la atención a Alemania, Inglaterra o Francia, entre otros, será relativamente inmediato darnos cuenta de que el mismo sintagma utilizado para describir la relación corrupta entre un particular y un funcionario (bribery o Bestechung) es también empleado para fotografiar situaciones que nada tienen que ver con la Administración pública.

Ahora bien, las conductas de corrupción o cohecho en el sector privado son aún lícitas en buena parte del mundo occidental (incluida la mayoría de los países hispano-hablantes). De ahí que el intento armonizador de la comunidad internacional (armonización que, conviene recordarlo, suele utilizar como modelo al país que más sanciona) haya sido impulsado en el sentido de que el mayor número posible de países incorporen medidas parecidas a las existentes en Estados cuyas empresas tienen prohibido recurrir a la práctica del soborno, bien sea de un funcionario público (nacional o extranjero), bien sea de un operador del mercado ajeno a la Administración. Por ello, en el marco del mencionado aumento de los instrumentos jurídicos supranacionales que mantienen como finalidad promover una armonización de la normativa penal anticorrupción, junto con la tradicional corrupción del funcionario público (nacional $\mathrm{y}$, como hemos visto, extranjero) se ha incorporado también la obligación para los países miembros de implementar un estándar punitivo mínimo en materia de corrupción entre particulares.

22 Obsérvese que esta conducta delictiva resulta incorporada de forma distinta en los Convenios internacionales. En la Convención Interamericana contra la Corrupción, su tipificación por parte de los países miembros es sólo parcialmente obligatoria (“con sujeción a su Constitución y a los principios fundamentales de su ordenamiento jurídico") y, en todo caso, la referencia es al mero cohecho transnacional activo; la medida se convierte en obligatoria en el convenio de OCDE, limitado también al Cohecho activo; la Convención de las Naciones Unidas contra la Delincuencia Organizada Transnacional, aconseja pero no obliga a tipificar como delito del cohecho del funcionario extranjero tanto activo como pasivo; finalmente, la Convención de las Naciones Unidas contra la corrupción obliga a tipificar como delito el cohecho activo del funcionario público extranjero y recomienda la tipificación del cohecho pasivo del funcionario público extranjero. 


\section{LAS PRINCIPALES INICIATIVAS INTERNACIONALES HACIA LA TIPIFICACIÓN DE UN DELITO DE "CORRUPCIÓN EN EL SECTOR PRIVADO"}

Dejando a un lado las razones que subyacen a la proliferación de herramientas jurídicas internacionales de lucha contra la corrupción y formulada una propuesta para justificar la progresiva inclusión en las mismas de preceptos cuya finalidad es la inclusión en el derecho nacional de un ilícito penal de cohecho entre particulares, no queda sino centrarnos ahora en el análisis de los principales instrumentos de derecho supranacional e internacional hoy en día existentes y que contienen medidas relacionadas con la tipificación de un delito de corrupción privada.

Limitado el análisis a aquellas herramientas jurídicas que interesan ahora por razones, en primer lugar, geográficas, conviene adelantar que la primera iniciativa supranacional que incorpora obligaciones para los países miembros de tipificar como delito la corrupción entre particulares fue la Acción Común 98/742/JAI, de 22 de diciembre de 1998 sobre la corrupción en el sector privado, adoptada por el Consejo europeo sobre la base del artículo K.3 del Tratado de la Unión Europea entonces vigente ${ }^{23}$. Siguiendo un orden meramente cronológico, encontramos dos preceptos que obligan a la tipificación del cohecho entre particulares también en la Convención de Derecho penal contra la Corrupción del Consejo de Europa que fue abierta a las firmas el día 27 de enero de 1999. Como veremos más adelante, debido al sustancial incumplimiento de la mencionada Acción Común, en el año 2003, la Unión Europea repitió la obligación en ella contenida, incorporándola a la Decisión Marco 2003/568/JAI del Consejo, de 22 de julio, relativa a la lucha contra la corrupción en el sector privado ${ }^{24}$. Finalmente, merece seguramente ser recordada como la iniciativa más relevante a escala planetaria la Convención de las Naciones Unidas contra la Corrupción que se abrió a las firmas en el mes de Diciembre de 2003 y que también contiene normas que promueven la tipificación de un delito de corrupción en el sector privado. Fuera del ámbito del derecho penal, finalmente, resulta útil mencionar también la presencia de la corrupción entre particulares en la Convención de Derecho Civil contra la Corrupción del Consejo de Europa, que se abrió a las firmas el día 4 de noviembre de 1999. 


\section{INSTRUMENTOS INTERNACIONALES ELABORADOS EN EL MARCO DEL CONSEJO DE EUROPA}

\subsection{La Convención de Derecho Civil contra la corrupción del Consejo de Europa}

Quizás pueda resultar sorprendente que exista un instrumento internacional de lucha contra la corrupción elaborado en el marco del Consejo de Europa que aborda la problemática de la erradicación de este pernicioso fenómeno desde el punto de vista del derecho civil. Por otro lado, para subrayar la coherencia de la aproximación al tema que nos atañe de esta organización internacional, hay que recordar que el Derecho Penal, correctamente entendido como ultima ratio del ordenamiento jurídico -es decir, como "el último de los recursos que el Estado tiene a su disposición para tutelar los bienes jurídicos" ${ }^{25}$ - interviene (o debería intervenir) "sólo cuando, para la protección de los bienes jurídicos merecedores de ella, se han puesto en práctica y resultan insuficientes medidas organizativas propias de otras ramas del Ordenamiento jurídico no represivas" ${ }^{26}$ : entre ellas, indudablemente, las que proporciona el derecho civil.

Dicho ello, el cuatro de noviembre de 1999, en la ciudad de Estrasburgo, el Consejo de Europa abrió a la firma (no sólo de sus Estados miembros ${ }^{27}$ ), la Convención de Derecho Civil de lucha contra la Corrupción ${ }^{28}$. En el preámbulo del texto definitivo, los Estados parte, se declaran "convencidos de la importancia del derecho civil en contribuir en la lucha contra la corrupción, en particular, al habilitar a las personas que hayan sufrido daños, para recibir una justa compensación”. De ahí que el artículo 1 de la Convención dispone que:

“Cada Estado parte proveerá su derecho interno de remedios efectivos para personas que hayan sufrido daños como resultados de actos de corrupción, para que

25 Berdugo Gómez de la Torre, I., y otros, Curso de Derecho penal, parte general, de. Experiencia, Barcelona, 2010, p. 72.

26 Berdugo Gómez de la Torre, I., y otros, Curso...cit., p. 73.

27 El Art. 15.1 del Convenio establece que: "esta Convención será abierta a la firma de los Estados miembros del Consejo de Europa, de los Estados no miembros que hayan participado en su elaboración y de la Comunidad Europea". Por otro lado, el Art. 16.1 dispone que "después de la entrada en vigor de este Convenio, el Comité de Ministros del Consejo de Europa, después de haberlo consultado con las Partes del Convenio, podrá invitar cualquier Estado no miembro del Consejo y que no ha participado en su elaboración para que acceda al Convenio, con una decisión tomada por la mayoría prevista en el artículo 20d del Estatuto del Consejo de Europa y con la unanimidad de los votos de las representaciones de las Partes que tengan título para participar en el Comité"

28 El texto del Convenio, el Explanatory Report y la tabla de ratificaciones (todo en lengua inglesa o francesa) son consultables a la página www.coe.int. 
puedan defender sus derechos e intereses, incluyendo la posibilidad de obtener un resarcimiento de los daños".

De forma distinta a la mayoría de las herramientas internacionales en vigor en la materia objeto de estudio, el Convenio, en su artículo 2, se preocupa de proporcionar una definición de lo que, para sus efectos, hay que entenderse por corrupción. A este respecto, es de destacar que el concepto adoptado incluye indistintamente tanto a la corrupción pública como a la privada, tanto a nivel nacional como transnacional o internacional. Así, se dice que:

\begin{abstract}
"para efecto de esta Convención, corrupción significa: requerir, ofrecer, dar o aceptar, directa o indirectamente, un soborno o cualquier otra ventaja indebida o perspectiva de ella, que distorsione el correcto cumplimiento de cualquier deber o comportamiento requerido por parte de quien recibe el soborno o la ventaja indebida o la perspectiva de ella".
\end{abstract}

Como resulta evidente del tenor literal de la norma, la definición tiene su clave de bóveda en el pago (o acuerdo de pago) de una ventaja para que el sujeto receptor incumpla un deber. En el caso de la corrupción pública, será relativamente inmediato identificar este deber en las normas (de derecho público) que regulan el comportamiento del funcionario público y su actuación en el ejercicio de sus funciones; en el caso de la corrupción privada, en cambio, habrá que hacer hincapié en aquellas normas que regulan la actuación de los sujetos en el mercado ${ }^{29}$.

Dicho ello, la definición, como es obvio, no necesita ser incluida textualmente en las legislaciones de los países signatarios del Convenio pero sí implica que éstos, a la hora de transponer las medidas contenidas en el mismo, deberán hacerlas aplicables a todos los casos subsumibles en el mencionado concepto. Y, como advierte el Reporte Explicativo anexo al propio Tratado, hay que subrayar que el Convenio tiene una finalidad relativamente amplia que refleja la aproximación del Consejo de Europa: la corrupción es considerada un problema que afecta no sólo al mundo de los negocios internacionales o de los intereses financieros, sino también a los valores democráticos, al Estado de derecho, a los derechos humanos, y al progreso social y económico ${ }^{30}$.

29 Resulta evidente y conviene resaltarlo desde ya que la correcta individualización de estos deberes determinará la elección del tipo de regulación que habrá que darse al fenómeno. Es evidente, en efecto, que, en el caso de la corrupción en el sector privado, existen deberes que apuntan a la tutela de intereses particulares (básicamente de origen contractual), deberes que apuntan a la tutela de intereses colectivos (piénsese a la regulación de la competencia leal) y normas que tutelan intereses generales (piénsese a la libertad de empresa y, a la tutela de los consumidores). Obsérvese también que estos intereses (en particular el interés del principal empresario, el interés de los competidores y el interés de los consumidores) pueden hallarse en una posición conflictiva entre ellos, que obligue a los legisladores nacionales a privilegiar una u otra perspectiva.

30 Traducción libre de Explanatory Report consultable a la página http://conventions.coe.int/Treaty/ en/Summaries/Html/174.htm en donde se afirma literalmente que "it is worth underlining, with respect to this definition, that the present Convention has, as one of its main characteristics, a relatively wide scope, which reflects the Council of Europe comprehensive approach to the fight against corruption as a threat not only to international business or to the financial interests but to the democratic values, the rule of law, human rights and social and economic progress". 
Con respecto a la disciplina prevista por la Convención, el artículo 3 de la misma obliga a los Estados parte a incluir en su legislación interna medidas que otorguen legitimación activa a las personas que hayan sufrido daños como consecuencia de corrupción para obtener una indemnización que incluya perjuicios materiales y no materiales, lucro cesante y daño emergente.

En materia de legitimación pasiva, según lo dispuesto por el artículo 4, la compensación procederá no sólo cuando el acusado haya cometido el acto de corrupción, sino que bastará con que lo haya autorizado o no haya tomado medidas razonablemente exigibles para prevenirlo. En este mismo sentido, destaca la responsabilidad patrimonial del Estado para los casos de corrupción pública (Art. 5).

Interesante también la disciplina que debe aplicarse a los contratos relacionados con prácticas corruptas: según establece el artículo 8 del Convenio, los Estados parte tienen que dotarse de herramientas legislativas que permitan declarar nulo todo contrato o cláusula contractual que tenga como objeto el pago de un soborno. A este respecto, el Reporte Explicativo subraya que, si es cierto que el pago o recepción de sobornos es práctica que suele ser ilegal en la mayoría de los derechos nacionales, no lo es menos que, si la causa del contracto es contraria a derecho, la misma resulta normalmente nula. En este marco, es preciso subrayar que la definición de corrupción proporcionada por la Convención incluye tanto a la corrupción pública como a la privada, de modo que, todo Estado parte, por lo menos a efecto de declaratoria de nulidad, deberá considerar nulo el contrato o cláusula contractual que tenga su causa en cualquiera de estas prácticas, con independencia de la existencia del relativo ilícito penal o administrativo en su ordenamiento jurídico interno.

Más relevante parece ser, de todas formas, el segundo apartado de la norma en cuestión que impone a los Estados parte legitimar activamente para la acción de nulidad a todos los contrayentes cuyo consentimiento haya sido prestado sobre la base de un acto de corrupción. Destaca, a este respecto, la legitimación limitada a las partes del contrato, sin perjuicio, se lee en el Reporte Explicativo, de que los Estados parte extiendan la legitimación a un más amplio abanico de sujetos.

Según el artículo 9 del propio texto, finalmente, cada Estado parte deberá adoptar medidas que garanticen una protección apropiada en contra de sanciones injustificadas para todos los empleados que tengan razonables sospechas de que haya habido corrupción y que reporten en buena fe sus sospechas a las personas o autoridades competentes. 


\subsection{La Convención de Derecho Penal contra la Corrupción del Consejo de Europa ${ }^{31}$}

El Consejo de Europa, reunido en Estrasburgo el 27 de enero de 1999, abrió a la firma y ratificación, tanto para los países miembros como para los Estados que hayan participado en su elaboración ${ }^{32}$, la Convención de Derecho Penal contra la Corrupción, texto jurídico que ha entrado en vigor el día 1 de julio de 2002, al lograrse las 14 ratificaciones necesarias. En el preámbulo de dicho texto normativo, los Estados Parte se declaran

"convencidos acerca de la necesidad de perseguir, como asunto prioritario, una política criminal común, con el fin de proteger la sociedad contra la corrupción, inclusive mediante la adopción de apropiadas medidas legislativas y preventivas"; desde el párrafo sucesivo del propio preámbulo, se precisa que el concepto de corrupción que tanto preocupa es algo distinto al proporcionado por la tradicional categorización de la dogmática penal: corrupción no es simplemente un comportamiento lesivo de la imparcialidad y del buen funcionamiento de la Administración Pública ${ }^{33}$, sino que representa una amenaza para

"el Estado de Derecho, la democracia y los derechos humanos, debilita el buen gobierno, la equidad y la justicia social, distorsiona la competencia, obstaculiza el desarrollo económico y pone en peligro la estabilidad de las instituciones democráticas y los fundamentos morales de la sociedad".

31 La tabla actualizada de los países que han firmado y ratificado este Convenio está disponible en la página http://conventions.coe.int/Treaty/Commun/ChercheSig.asp? $\mathrm{NT}=173 \& \mathrm{CM}=8 \& \mathrm{DF}=4 / 4 / 20$ 08\&CL=ENG. El texto oficial del Convenio está disponible en la página http://conventions.coe.int/ Treaty/en/Treaties/Html/ 173.htm.

32 Y abierta también al acceso de todo demás país. A la fecha de hoy, la Convención ha sido ratificada por Bielorrusia y ha sido firmada por México y por Estados Unidos.

33 Sostienen que "imparcialidad" y "buen funcionamiento" de la Administración Pública representan el bien jurídico protegido por los delitos de corrupción, entre otros: Segreto, A. -De Luca, G., I delitti dei pubblici ufficiali contro la pubblica amministrazione, II ed., Giuffrè, Milano, 1995, pp. 453 y ss.; Vassalli, G., "Corruzione propria e corruzione impropria", en La Giustizia Penale, 1979, p. 326; Bricola, F., "Tutela penale della Pubblica amministrazione e principi costituzionali”, en Temi, 1968 págs. 563 y ss.; Dupuis M. B., La corruzione, CEDAM, Padua, 1995; Mirri M.b., "I delitti di corruzione: disciplina positiva e prospettive di riforma", en La Giustizia Penale, 1987, p. 130; Tagliarini, F., Il concetto di Pubblica Amministrazione nel codice penale, Giuffrè, Milano, 1973, pp. 189 y ss.; para un referencia al principio de im parcialidad de la actividad de la Administración Pública como bien jurídico protegido por los delitos de cohecho véase también Valeije Álvarez, I., El tratamiento penal de la corrupción del funcionario: el delito de cohecho, Editoriales de Derecho Reunidas, Madrid, 1995, pp. 25 y sgts; Rodriguez Puerta, M.J., El delito de cohecho: problemática jurídico-penal del soborno de funcionarios, Aranzadi, Pamplona, 1999, pp. 66 y ss.; sostienen que el bien jurídico protegido por los delitos de cohecho es el "correcto funcionamiento de la Administración Pública" Olaizola Nogales, I., El delito de Cohecho, Tirant lo Blanch, Valencia, 1999, pp. 89 y ss. 
Precisamente la consideración de tan amplias y diversas consecuencias producidas por comportamientos "corruptos" parece motivar la tipificación, junto con la tradicional corrupción "pública" (artículos 1-6), del cohecho en el sector privado (artículos 7 y 8). Como se lee en el Explanatory Report ${ }^{34}$ anexo a la Convención, la extensión de la responsabilidad criminal a la corrupción (bribery) en el sector privado se debe principalmente a que:

a. Según los compiladores del Convenio, los actos de corrupción en el sector privado representan una vulneración de los valores de lealtad y confianza necesarios para el mantenimiento y el desarrollo de las relaciones sociales y económicas. El menoscabo de estos valores es consecuencia tanto de la corrupción en el sector público como del soborno en el sector privado, lo que desautoriza a regular de forma distinta relaciones iguales con el sólo argumento que las unas conciernen al sector público y las otras al sector privado $^{35}$.

b. En segundo lugar, la penalización de la corrupción en el sector privado es necesaria para asegurar el respeto de la competencia leal ${ }^{36}$.

c. En tercer lugar, la sanción penal de la corrupción en el sector privado es consecuencia de los masivos procesos de privatización que han tenido lugar en las últimas décadas. La transposición de actividades de público interés en ámbitos ajenos a la Administración pública ha sido acompañada por una transferencia de poderes de regulación y de parte del presupuesto al sector privado; por ello, parece lógico proteger el público de los efectos dañinos de la corrupción privada, en particular debido a que tanto la financiación como otros poderes concentrados en el sector privado han adquirido un gran importancia social ${ }^{37}$.

34 Cuyo texto integral en inglés es consultable a la página: http://conventions.coe.int/Treaty/en/ Reports/Html/ 173.htm.

35 Literalmente: "corruption in the private sphere undermines values like trust, confidence or loyalty, which are necessary for the maintenance and development of social and economic relations. Even in the absence of a specific pecuniary damage to the victim, private corruption causes damage to society as a whole. In general, it can be said that there is an increasing tendency towards limiting the differences between the rules applicable to the public and private sectors. This requires redesigning the rules that protect the interests of the private sector and govern its relations with its employees and the public at large".

36 Literalmente: "Secondly, criminalisation of private sector corruption was necessary to ensure respect for fair competition".

37 Literalmente "Thirdly, it also has to do with the privatisation process. Over the years important public functions have been privatised (education, health, transport, telecommunication etc). The transfer of such public functions to the private sector, often related to a massive privatisation process, entails transfers of substantial budgetary allocations and of regulatory powers. It is therefore logical to protect the public from the damaging effects of corruption in businesses as well, particularly since the financial or other powers concentrated in the private sector, necessary for their new functions, are of great social importance". Sobre la falta de relación proporcional entre privatización y disminución del nivel de corrupción, véase LORA E. -PANIZZA U., "Globalización 
Por estas razones, el artículo 7 del Convenio (bajo el título Active Bribery in the Private Sector) dispone que:

"Cada Parte adoptará las medidas legislativas y de otra índole que sean necesarias para tipificar como delito, conforme a su derecho interno, cuando se cometa intencionalmente en el curso de una actividad mercantil, el hecho de prometer, ofrecer u otorgar, directa o indirectamente, cualquier ventaja indebida a una persona que dirija o trabaje en cualquier calidad para una entidad del sector privado, para sí misma o para cualquier otra persona, con el fin de que realice o se abstenga de realizar un acto incumpliendo sus deberes" ${ }^{\prime 38}$.

El sucesivo artículo 8 regula la introducción de la corrupción pasiva en el sector privado (Pasive Bribery in the Private Sector), estableciendo la obligación, para todo Estado Parte, para que adopte
"las medidas legislativas y de otra índole que sean necesarias paratipificar como delito, conforme a su derecho interno, cuando se cometa intencionalmente en el curso de una actividad mercantil, el hecho de que una persona que dirija o trabaje en cualquier calidad para una entidad del sector privado solicite o reciba, directamente o por mediación de terceros, una ventaja indebida o de que acepte la oferta o promesa de esa ventaja, para sí misma o para cualquier otra persona, con el fin de que realice o se abstenga de realizar un acto incumpliendo sus deberes" 39 .

Según el Reporte Explicativo anexo al Convenio, salta a la vista que la estructura general del tipo "corrupción en el sector privado" refleja, mutatis mutandis, la tradicional sanción de la corrupción pública (entendida como cohecho) ${ }^{40}$. En la tipificación del soborno, por un lado, está un sujeto (cualquiera) que promete, ofrece o da una ventaja indebida y se dirige a otro sujeto "calificado" (en el caso de la corrupción pública, un servidor público) que recibe o acepta la promesa o el ofrecimiento (o lo solicita, conducta que, en algunos países, configura una tentativa ${ }^{41}$ ).

Dicho ello y remitiendo el lector al Explanatory Report para un análisis de los elementos comunes a estos dos géneros de corrupción ${ }^{42}$, es preciso, a efectos de

y reformas estructurales en América latina: lo que funcionó y lo que no", en Revista Asturiana de Economía, No. 24, 2002, pp. 27 y ss.

38 La traducción al español es la incluida en el BOE de 28 de julio de 2010 en el cual se publica el instrumento de ratificación del Convenio del Reino de España.

39 La traducción al español es la incluida en el BOE de 28 de julio de 2010 en el cual se publica el instrumento de ratificación del Convenio del Reino de España.

40 En este sentido, Ferré Olivé, J.C., "Corrupción en el sector privado”, en AA.VV., Corrupción en el sector privado, Material z konferencji w Krakowie, 10-13, Lipca, 2003, Wydawnichtwo Naukowe SCHOLAR, Varsovia, 2004, p. 28

41 Cfr. Art. 322 del código penal italiano.

42 Para un análisis más completo de las disposiciones del convenio en materia de corrupción en el sector privado, se remite a De La Cuesta Arzamendi, J. L. -Blanco Cordero, I., "La criminalización 
este trabajo, detenernos sobre los aspectos del tipo que caracterizan la "corrupción privada" respecto de la tradicional figura del cohecho de funcionario público, a saber:

1. Los sujetos calificados. Los delitos de corrupción se caracterizan por la participación necesaria de dos sujetos que podríamos definir como "comprador" y "vendedor" de una actividad. En el caso de la tradicional corrupción pública, pudiendo ser "cualquiera" el primero de ellos, suele circunscribirse el abanico de los posibles sujetos vendedores a aquellos que desempeñan una actividad, de alguna forma, relacionada con lo público: suele hablarse, a este respecto, de "funcionarios públicos", "empleados públicos", "servidores públicos", "autoridades" y otros. Ahora bien, es evidente que la primera característica de la corrupción privada es justamente el hecho de ser "privada", es decir, no-pública, por lo que asumen relevancia conductas que involucran a sujetos no-públicos. De ahí que, en una primera aproximación, la determinación de los posibles sujetos activos de cohecho pasivo público determinará, por defecto, la categoría de sujetos posibles autores de corrupción pasiva en el sector privado $^{43}$.

Dicho ello, a tenor de lo dispuesto por el Convenio que se analiza, realiza actos de corrupción privada pasiva penalmente punibles no todo sujeto "no-público" que "venda" una actuación (u omisión) violando sus deberes, sino que el tipo penal exige, para que la conducta asuma relevancia, que el sujeto calificado tenga alguna relación con una "entidad" privada -esto es, en síntesis, el sentido de la dicción "toda persona que dirige o trabaja, en cualquier posición para una entidad del sector privado"-. Con respecto a la "relación" con la entidad, el Reporte Explicativo exige una interpretación amplia ${ }^{44}$, que incluye a todo tipo de relación empleado-empleador, además de acuerdos comerciales, relaciones abogado-cliente, asesorías, relaciones de agencia y otras equiparables, con independencia de su base en un contrato laboral. Por lo que concierne a los directivos, se consideran incluidos como posibles sujetos activos del delito de corrupción pasiva los managers, todos los miembros de la junta directiva y todo el que, en general, recubre un cargo en la empresa (quedan así excluidos los simples accionistas). Por lo que respecta a la "entidad del sector privado", se explica que se considera privada toda entidad cuyo propietario (enteramente o como accionista mayoritario) sea un particular. Finalmente, entidad incluye no sólo a las personas jurídicas sino también a las personas físicas que, de alguna manera, ejercen una actividad comercial.

de la corrupción en el sector privado: ¿Asignatura pendiente del derecho penal español?”, en Diez Ripollés, J. L. (COORD.), La ciencia del derecho penal ante el nuevo siglo: libro homenaje al profesor doctor don José Cerezo Mir, Tecnos, Madrid, 2002, pp. 259 y ss.

43 En el caso de la Convención del Consejo de Europa contra la Corrupción, el texto legislativo deja completa libertad a los Estados Miembros, y establece que,como es sujeto activo del delito de cohecho el "funcionario público" (public oficial), dicha categoría ha de entenderse según la definición que de ella proporciona el ordenamiento nacional en el que el sujeto presta sus funciones

44 Cfr. MUSCO E., "Politica criminale in materia di corruzione privata", en AA.VV., Corrupción en el sector privado cit., p. 34. 
2. El elemento subjetivo. Tradicionalmente, el tipo penal de cohecho no sanciona el ejercicio contrario a derecho de la actividad de un servidor público, sino que establece una pena para aquel sujeto público (y para el particular) que acepta una remuneración para ejercer (u omitir ejercer) su actividad o por haberla ejercido. En la construcción del tipo penal, ello se refleja en la estructura del elemento subjetivo: se requiere que ambos sujetos involucrados se representen que la remuneración se promete, da, ofrece, solicita, acepta .. o bien por un acto (o una actuación) ya realizados, o bien, para la realización de un acto (o actuación), con independencia, en este segundo caso, de que el acto (o actuación) efectivamente se produzca. Ahora bien, típicamente se distingue entre una corrupción antecedente o subsiguiente, según que la actuación del sujeto público sea respectivamente anterior o sucesiva respecto del acuerdo remuneratorio. De la misma manera, el cohecho será impropio o propio según que el acto (o actuación) pactado, de por sí, sea conforme o contrario a los deberes del sujeto público, respectivamente. En el caso de la corrupción en el sector privado, el Convenio que ahora se analiza considera que hay que establecer una sanción penal para los casos de corrupción antecedente propia (esto es, la remuneración de un acto futuro y contrario a los deberes de quien se compromete a realizarlo). Dicho ello, distinguir los casos de cohecho en el sector privado antecedente y subsiguiente no representa un problema; mayores dificultades entraña, en cambio, la acotación del tipo de corrupción privada propia ya que no resulta inmediata la individualización de aquellos deberes cuya violación es relevante de acuerdo con el tipo penal (pudiéndose discutir, por ejemplo, acerca de la relevancia de los solos deberes contractuales o también de todos los deberes legalmente establecidos). A este respecto, de forma amplia y, según algunos, imprecisa ${ }^{45}$, el Explanatory Report aclara que la criminalización de la corrupción en el sector privado busca la protección de la confianza y de la lealtad que son indispensables para la propia existencia de las relaciones entre particulares. De ahí que los “deberes" a los que hace referencia la norma no abarcan sólo derechos y obligaciones de origen contractual sino que incluyen también a toda vulneración del genérico deber de lealtad que el dependiente, el manager o el directivo asumen hacia el empresario: ello, según los compiladores, justificaría la sanción penal para todo el que recibe un soborno para actuar (u omitir una actuación) vulnerando este deber de lealtad.

3. La conducta penalmente relevante. "Corrupción privada", hemos dicho, es, en primera instancia, la actuación corrupta que involucra a un sujeto "no-público" vinculado con una "entidad" en las formas antes especificadas. Pero ello no basta. Para que el pago de un soborno entre particulares asuma relevancia penal, a efectos de lo dispuesto por la Convención de derecho penal del Consejo de Europa contra

45 En este sentido Seminara S., "sin título", en Acquaroli R. -Foffani L., (a cura di), La Corruzione tra privati, esperienze comparatistiche e prospettive di reforma, atti del convegno, Jesi (AN), 12-13 aprile 2002, Giuffrè, Milano, 2003, p. 273. 
la Corrupción, es necesario que ello tenga lugar "en el marco de una actividad comercial". Como aclara el Reporte Explicativo, no obstante queden así excluidas las actividades non-profit oriente ${ }^{46}$, la expresión "actividad comercial" tiene que interpretarse en sentido amplio, incluido todo tipo de actividad, con particular respecto al comercio de bienes y a la prestación de servicios.

\section{LA UNIÓN EUROPEA Y LA LUCHA CONTRA LA CORRUPCIÓN EN EL SECTOR PRIVADO}

Los dos instrumentos que a continuación se analizarán se presentan como jurídicamente distintos con respecto a los anteriormente mencionados ${ }^{47}$. Se trata, en efecto, de una "Acción común" y de una "Decisión marco" del Consejo Europeo (órgano de la Unión).

Como instrumento jurídico del antiguo Título VI del Tratado de la Unión Europea, la "Acción común" se utilizó entre 1993 y 1999. En el marco de las "Disposiciones relativas a la cooperación en los ámbitos de la justicia y de los asuntos de interior"48,

46 Dicha previsión, aclara el Explanatory Report, no constituye obstáculo alguno para que los Estados que ratifiquen este instrumento jurídico extiendan la sanción penal a conductas realizadas por este tipo de entidades.

47 La mencionada iniciativa del Consejo de Europa, como se ha visto, tiene forma de un Convenio Internacional cuya obligatoriedad está sujeta a la firma y ratificación por parte de los Estados miembros. El artículo 37 del propio Convenio, además, permite a los países formular "reservas" con respecto a la transposición en su derecho interno de los delitos tipificados con arreglo a los artículos 6 y 7 de la Convención, es decir, de la corrupción en el sector privado. De igual manera, ya hemos hecho referencia al hecho que el Convenio está abierto a la firma no sólo por parte de aquellos países miembros del Consejo.

48 El art. K.1 T.U.E. (con el que se da inicio al Título VI), en su versión precedente al tratado de Ámsterdam, definía los ámbitos de interés común en el marco de la cooperación en los ámbitos de la justicia y de los asuntos de interior. En este ámbito, decía el Tratado, "para la realización de los fines de la Unión, en particular de la libre circulación de personas, y sin perjuicio de las competencias de la Comunidad Europea, los Estados miembros consideran de interés común los ámbitos siguientes: 1) La política de asilo; 2) Las normas por las que se rigen el cruce de personas por las fronteras exteriores de los Estados miembros y la práctica de controles sobre esas personas.

3) La política de inmigración y la política relativa a los nacionales de terceros Estados acerca de: a) las condiciones de acceso al territorio de los Estados miembros y de circulación por el mismo de los nacionales de terceros Estados; b) las condiciones de estancia de los nacionales de los terceros Estados en el territorio de los Estados miembros, incluidos el acceso al empleo y la reagrupación familiar; c) la lucha contra la inmigración, la estancia del trabajo irregulares de nacionales de los terceros Estados en el territorio de los Estados miembros; 4) La lucha contra la toxicomanía en la medida en que dicha materia no esté cubierta por los apartados 7 a 9 siguientes; 5) La lucha contra la defraudación a escala internacional en la medida en que dicha materia no esté cubierta por los apartados 7 a 9 siguientes; 6) La cooperación judicial en materia civil; 7) La cooperación judicial en materia penal; 8) La cooperación aduanera; 9) La cooperación policial para la prevención y la lucha contra el terrorismo, el tráfico ilícito de drogas y otras formas graves de delincuencia internacional, incluidos, si es necesario, determinados aspectos de la cooperación aduanera en conexín con la 
este término designaba una acción coordinada de los Estados miembros, en el nombre o en el marco de la Unión, a adoptarse cuando los objetivos de la Unión podían salir más beneficiados mediante una acción conjunta que mediante la actuación de los Estados miembros de forma aislada, debido a las dimensiones o a los efectos de la acción prevista ${ }^{49}$

El Tratado de Ámsterdam suprimió la “Acción común” como "instrumento normativo del tercer pilar" (copoperación policial y judicial en materia penal) y la sustituyó por las “decisiones ${ }^{50}$ y "decisiones marco". Estas últimas ${ }^{51}$ se utilizaban para la aproximación de las disposiciones legales y reglamentarias de los Estados miembros, que quedaban obligados en cuanto a la consecución del resultado, pudiendo las autoridades nacionales elegir la forma y los medios para su alcance ${ }^{52}$. La Decisión marco, según establecía el artículo 34 b) TUE no tenía, como las directivas, un efecto directo. Ello, no obstante, la jurisprudencia del TJCE ha venido reconociendo su efecto indirecto que se sustancia en la obligación para el juez nacional de interpretar -en el respeto del principio de legalidad-, el Derecho nacional de forma conforme a los establecidos por las decisiones marco ${ }^{53}$.

Con la entrada en vigor del Tratado de Lisboa, ambas herramientas jurídicas han desaparecido, junto con la división en pilares del derecho comunitario. Ello no obstante, de momento, los actos normativos válidamente adoptados en el marco del

organización, a escala de la Unión, de un sistema de intercambios de información dentro de una Oficina Europea de Policía (Europol). El sucesivo artículo K.3 disponía que en los ámbitos a que se refiere el artículo K.1, los Estados miembros se informarán y consultarán mutuamente en el seno del Consejo, con objeto de coordinar su acci6n. A tal fin establecerán una colaboraci6n entre los servicios competentes de sus respectivas administraciones. 2. EI Consejo podrá, -a iniciativa de cualquier Estado miembro o de la Comisi6n en las materias contempladas en los puntos 1 a 6 del artículo K.1; a iniciativa de cualquier Estado miembro en las materias contempladas en los puntos 7 a 9 del artículo K.1; a) adoptar posiciones comunes y fomentar, en la forma y según los procedimientos oportunos, toda forma de cooperaci6n pertinente para la consecución de los objetivos de la Unión; b) adoptar acciones comunes, en la medida en que los objetivos de la Unión puedan alcanzarse más fácilmente por medio de una acci6n común que por la acción aislada de los Estados miembros en raz6n de las dimensiones o de los efectos de la acci6n de que se trate: el Consejo podrá decidir que las medidas de aplicación de una Acción común sean aprobadas por mayoría cualificada; c) sin perjuicio de lo dispuesto en el artículo 220 del Tratado constitutivo de la Comunidad Europea, celebrar convenios recomendando su adopci6n a los Estados miembros según sus respectivas normas constitucionales".

49 http://europa.eu/scadplus/glossary/joint_action_jha_es.htm.

50 Artículo 34.2.c TUE.

51 Artículo 34.2.b. TUE.

52 Este instrumento de cooperación desaparecerá con la entrada en vigor del Tratado de Lisboa.

53 Cfr. en este sentido, la Sentencia TJCE C-105/03 en materia de Decisión marco 2001/220/JAI del Consejo, de 15 de marzo de 2001, relativa al estatuto de la víctima en el proceso penal. cfr. Castillo García, J.f., La comunitarización del tercer pilar: un paso necesario para la consolidación del espacio penal europeo, en Revista General de Derecho europeo, n. 11, 2006, en IUSTEL RI $\S 794239$, p. 5 y ss. 
tercer pilar antes de la entrada en vigor del mencionado Convenio mantendrán la misma eficacia ${ }^{54}$.

\subsection{La Acción común de 22 de diciembre de 1998 sobre la corrupción en el sector privado ${ }^{55}$}

Con respecto a la Convención de derecho penal antes analizada, la Acción común tiene un objeto más limitado, lo que se refleja en su preámbulo. Se recordará que el Convenio del Consejo de Europa considera que la corrupción en el sector privado genera un quebrantamiento del deber de "lealtad" en las relaciones comerciales, altera la leal competencia y que su represión es necesaria para hacer frente a la desregulación que los fenómenos de privatización han venido produciendo. La Acción común se limita a hacer referencia al segundo punto, al considerar que:

"la corrupción falsea la competencia leal y compromete los principios de apertura y libertad de los mercados, y, en concreto, el correcto funcionamiento del mercado interior, y es contraria a la transparencia y la apertura del comercio internacional".

El artículo 4 del texto legal de quo, obliga a los Estados miembros a adoptar las medidas necesarias para asegurar que las conductas de corrupción activa y pasiva en el sector privado, así como la complicidad o la instigación a las mismas, sean objeto de sanciones penales eficaces, proporcionadas y disuasorias que incluyan, al menos en los casos graves, penas privativas de libertad que puedan dar lugar a la extradición. Aparte de ello, el artículo 5 obliga los Estados miembros a introducir sanciones de naturaleza penal o administrativa para las personas jurídicas responsables de corrupción activa en el sector privado (véanse Anexos VI y VII).

Los artículos 2 y 3 de la Acción común incluyen las definiciones de Corrupción pasiva y activa en el sector privado, respectivamente.

En particular, el artículo 2 establece que:

"a efectos de la presente Acción común, constituirá corrupción pasiva en el sector privado el acto intencionado de una persona que, directamente o por medio de terceros, solicite o reciba en el ejercicio de actividades empresariales ventajas indebidas de cualquier naturaleza, para sí misma o para un tercero, o acepte la promesa de tales ventajas, a cambio de realizar o abstenerse de realizar un acto incumpliendo sus obligaciones".

El sucesivo artículo 3 dispone que:

54 Véase, sobre este punto, lo dispuesto por el Protocolo 36 "sobre las disposiciones transitorias" anexo al Tratado de Lisboa y precisamente en su título VII que incluye las "disposiciones transitorias relativas a los actos adoptados en virtud de los títulos V y VI del tratado de la unión europea antes de la entrada en vigor del Tratado de Lisboa" con particular respecto al artículo 10 párrafos 1 y 3 .

55 Diario Oficial, n. L. 358 de 31 de diciembre de 1998. Texto consultable a la página http://eur-lex. europa.eu/LexUriServ/LexUriServ.do?uri=CELEX:31998F0742:ES:HTML 
“a efectos de la presente Acción común, constituirá corrupción activa en el sector privado la acción intencionada de quien prometa, ofrezca o dé, directamente o por medio de terceros, una ventaja indebida de cualquier naturaleza a una persona, para ésta o para un tercero, en el ejercicio de las actividades empresariales de dicha persona, para que ésta realice o se abstenga de realizar un acto incumpliendo sus obligaciones".

Analizando brevemente el tipo penal, conviene destacar la definición de los sujetos calificados posibles autores del delito de corrupción pasiva en el sector privado y la relevancia de las solas conductas que tengan como finalidad un "incumplimiento de las obligaciones" de los mismos:

1. Sujetos calificados. A primera vista, el texto legislativo en cuestión configura la corrupción pasiva en el sector privado como delito común, al atribuir relevancia penal a conductas realizadas por una "persona". No obstante, el artículo 1 de la Acción común aclara que el término persona designa a "cualquier asalariado o cualquier otra persona cuando desempeñe funciones directivas o laborales de cualquier tipo para una persona física o jurídica que opere en el sector privado o en su nombre".

2. El objeto del dolo específico: el incumplimiento de obligaciones. Al igual que en la Convención de Derecho Penal contra la Corrupción, la Acción común limita el ámbito de lo penalmente prohibido a los casos de corrupción propia antecedente, exigiéndose que la futura actuación del sujeto vendedor suponga un "incumplimiento de sus obligaciones". Aclara el artículo 1.3. de la Acción común que la expresión "incumplimiento de obligaciones" tiene que entenderse conforme al Derecho nacional, debiéndose incluir, como mínimo, cualquier comportamiento desleal que constituya un incumplimiento de una obligación legal o, en su caso, de las normas o reglamentos profesionales que se aplican en el sector mercantil" ${ }^{15}$.

Con respecto a la eficacia de las disposiciones contenidas en la Acción común, el artículo 8 del texto legal establece que los Estados miembros tendrán un plazo de dos años a partir de la entrada en vigor de la misma para presentar propuestas adecuadas con objeto de que las autoridades competentes las estudien con vistas a su adopción. El Consejo, por su parte, prevé la elaboración de un informe acerca del cumplimiento por parte de los Estados miembros de las obligaciones derivadas de la Acción común a finalizarse tres años después de su entrada en vigor.

56 Como apuntan De La Cuesta Arzamendi, J. L., -Blanco Cordero, I., (ob. cit., p. 263), a la vista del tenor literal de la norma resulta por lo menos dudosa la relevancia de la aceptación de un "soborno" autorizada por el empresario. Los autores ponen el ejemplo del encargado de ventas que acepta un premio a cambio de actuar "incumpliendo sus obligaciones" con el consentimiento del empresario-principal. Estimamos, sin embargo que, debido a lo establecido por los artículos 2.3. y 3.3., deberá ser objeto de sanción toda conducta "que suponga o pueda suponer una distorsión de la competencia, al menos en el marco del mercado común y que cause o pueda causar perjuicios económicos a terceros debido a la adjudicación o la ejecución irregular de un contrato". 
Dicho ello, el texto legal matiza la obligación de tipificar como delito las conductas referidas: los arts. 2.2 y 3.2 obligan a los Estados miembros para que adopten las medidas necesarias para asegurar que las conducta de corrupción activa y pasiva en el sector privado se tipifiquen como infracción penal, como mínimo, cada vez que supongan o puedan suponer una distorsión de la competencia, al menos en el marco del mercado común y que causen o puedan causar perjuicios económicos a terceros debido a la adjudicación o la ejecución irregular de un contrato. A parte de ello, el propio texto legal faculta a todo Estado miembro para que establezca sanciones de naturaleza distinta a la penal para los casos menos graves (art. 4.2.) ${ }^{57}$.

\subsection{La Decisión marco del Consejo Europeo de 22 de Julio de 2003 relativa a la lucha contra la corrupción en el sector privado ${ }^{58}$}

No obstante la obligación contenida en el artículo 8 de la Acción común analizada en al párrafo precedente, a fecha dos de agosto de 2002, cinco países miembros ${ }^{59}$ no habían tipificado delito alguno de corrupción en el sector privado ${ }^{60} \mathrm{y}$ otros muchos tenían normas no completamente ajustadas al estándar mínimo requerido por la Acción común. Esta falta de eficacia del instrumento jurídico comunitario analizado anteriormente, junto con la evolución de la forma jurídica de las iniciativas comunitarias en el ámbito del "tercer pilar", empujó el Consejo Europeo a adoptar, cinco años después de la Acción común, por la iniciativa del Reino de Dinamarca, una Decisión marco con el objetivo de "asegurar que la corrupción activa y pasiva en el sector privado sea una infracción penal en todos los Estados miembros" $"$.

El artículo 4 de este texto legal obliga a los Estados miembros a que tomen las medidas necesarias para asegurar que los actos de corrupción activa y pasiva en el sector privado sean punibles con sanciones penales efectivas, proporcionadas y

57 Cfr. De La Cuesta Arzamendi J. L. - Blanco Cordero, I., ob. cit., pp . 263-266.

58 Diario oficial de las Comunidades Europeas L 192/54 de 31 de julio de 2003, consultable la página http://eur-lex.europa.eu/LexUriServ/LexUriServ.do?uri=OJ:L:2003:192:0054:0056:ES:PDF. Aunque no sea argumento de este trabajo, es preciso notar que el marco jurídico en el que ha sido adoptada la decisión resiente de la pronuncia de la sentencia C-176/03 del Tribunal de justicia de las Comunidades Europeas relativa al reparto de competencias en materia penal entre la Comisión Europea y el Consejo de la Unión Europea. Sobre este punto, entre otros cfr. NIETO MARTÍN, A., "Fundamentos constitucionales del sistema europeo de derecho penal", en Revista General de Derecho Penal, No. 3 Mayo 2005, passim (consultado en versión electrónica).

59 En España, la primera "propuesta" en la materia tiene fecha de enero de 2007. Por otro lado, otros países como Italia introdujeron tipos penales que mal o poco se ajustan a los requerimientos contenidos en el texto legal comunitario mencionado.

60 Palomo De Arco, A., "El delito de corrupción en el sector privado como ejemplo de incidencia del derecho comunitario en el derecho penal de los Estados miembros", en AA.VV., La corrupción en el sector privado...cit., p. 82.

61 Así el décimo "considerando" de la Decisión marco. 
disuasorias que incluyan una pena privativa de libertad de duración máxima de al menos de uno a tres años. Exige además la Decisión marco que, a toda persona física condenada por corrupción en el sector privado, al menos en los casos en que haya ocupado un puesto destacado en la empresa dentro del ramo de actividad de que se trate, se le prohíba temporalmente el ejercicio de esa actividad profesional o de una actividad comparable en un puesto o función similares, cuando los hechos comprobados den motivos para pensar que existe un claro riesgo de que abuse de su posición o cargo mediante actos de corrupción activa y pasiva. Finalmente, los artículos 5 y 6 exigen la adopción de sanciones para personas jurídicas responsables de corrupción en el sector privado, tanto en su vertiente activa, como pasiva (véanse Anexos VI y VII).

El artículo 2 aclara que los actos de corrupción activa y pasiva a sancionarse penalmente por los Estados miembros son:

"Prometer, ofrecer o entregar intencionadamente, directamente o a través de un intermediario, a una persona que desempeñe funciones directivas o laborales de cualquier tipo para una entidad del sector privado ${ }^{62}$, una ventaja indebida de cualquier naturaleza para dicha persona o para un tercero, para que ésta realice o se abstenga de realizar un acto incumpliendo sus obligaciones".

"Pedir, recibir intencionadamente, directamente o a través de un intermediario, una ventaja indebida de cualquier naturaleza, o aceptar la promesa de tal ventaja, para sí mismo o para un tercero, cuando se desempeñen funciones directivas o laborales de cualquier tipo para una entidad del sector privado, a cambio de realizar o abstenerse de realizar un acto incumpliendo sus obligaciones, siempre y cuando dichas actuaciones se produzcan en el marco de actividades profesionales de entidades con fines lucrativos y no lucrativos".

Así como hemos hecho con respecto a las normas anteriormente citadas, conviene limitarnos a analizar los elementos más significativos del tipo penal que se obliga a introducir en el derecho interno de los Estados miembros:

1. El incumplimiento de las obligaciones: el objeto del dolo específico del

62 Algunos autores (Musco E., "Politica criminale in materia di corruzione privata", en AA.VV., Corrupción en el sector privado...cit., loc. cit.; Ferrè Olivè, J. C., ob. cit., loc. Cit.) apuntan la excesiva amplitud de la dicción "entidad del sector privado". Sin querer aquí enfrentarnos a la cuestión de si es tarea del legislador comunitario delimitar exactamente el alcance de la norma o si más bien la competencia sobre el punto es del legislador nacional, recordamos como el punto noveno del preámbulo de la Decisión marco recoge el empeño de "los Estados miembros que todavía no han ratificado el Convenio de la Unión Europea de 27 de enero de 1999" a estudiar el modo de hacerlo lo antes posible. Se recordará que el Explanatory Report anexo a este convenio contiene algunas notas interpretativas en materia del alcance de la dicción "entidad en el sector privado" que bien pueden resultar útil a la hora de adoptar la Decisión marco que se comenta. 
delito de corrupción privada, así como acontecía en el delito configurado por la Acción común de 1998, consiste en la actuación (u omisión) del sujeto calificado que suponga un incumplimiento de sus obligaciones. El artículo 1 del texto legal aclara que "la expresión incumplimiento de las obligaciones se entenderá conforme al derecho nacional”. Para asegurar un estándar mínimo de protección, se exige que

"el concepto del incumplimiento de las obligaciones en el Derecho nacional deberá incluir como mínimo cualquier comportamiento desleal que constituya un incumplimiento de una obligación legal o, en su caso, de las normas o reglamentos profesionales que se aplican en el sector de actividad de que se trate a una persona que desempeñe funciones directivas o laborales de cualquier tipo para una entidad del sector privado" ${ }^{3}$.

2. La referencia a la distorsión de la competencia: ya al hablar de la Acción común de 1998 hemos insistido sobre las motivaciones que, de cierta manera, hacen referencia a las consecuencias negativas que la corrupción privada produce sobre la leal competencia. Sin perjuicio de volver más adelante sobre el tema, es de destacar cómo la Decisión marco de 2003 atribuye particular importancia a este punto. "Los Estados miembros", se lee en noveno considerando del preámbulo,

"conceden una importancia especial a la lucha contra la corrupción en el sector público como en el privado, por estimar que en ambos sectores, constituye una amenaza para el Estado de Derecho, al tiempo que distorsiona la competencia respecto de la adquisición de bienes o servicios comerciales e impide un desarrollo económico sólido". La distorsión de la competencia no aparece sólo como ratio

63 Al igual que en la Acción común de 1998, la definición de "incumplimiento de las obligaciones" aparece relativamente amplia, pivotando sobre un concepto de "deslealtad" que necesitará de una determinación a la hora de implementarse lo dispuesto por la Decisión marco. Nos sumamos, en este sentido a las críticas avanzadas al texto de la Decisión marco por algunos autores (entre ellos Ferré Olivé, J.C., "Corrupción en el sector privado", en AA.VV., Corrupción en el sector privado... cit., loc. cit.). El mismo autor observa, de forma igualmente crítica, como la Unión Europea, después de declarar que la expresión "incumplimiento de las obligaciones" ha de entenderse conforme establece el derecho interno de todos los países, en realidad termina disponiendo de forma "inapropiada" como el derecho nacional debe definirla. La observación tiene que ver, estimamos nosotros, con los límites a los que está sujeto el derecho comunitario en materia penal, límites que se han visto afectados por la sentencia C-176/03 del Tribunal de Justicia de las Comunidades Europeas relativa al reparto de competencias en materia penal entre la Comisión Europea y el Consejo de la Unión Europea. El debate traspasa el objeto de este trabajo en donde sólo cabe afirmar que, en principio, cada esclarecimiento normativo a nivel comunitario que tenga la finalidad de armonizar los derechos internos de los países miembros ha de ser visto, en nuestra opinión, con favor, sin perjuicio de que la técnica legislativa utilizada pueda ser objeto de crítica. Muy crítico hacia la adopción de esta iniciativa comunitaria es también MUSCO E., "Politica criminale...", cit. Pág. 40. Sobre este punto véase también la nota precedente. 
de la disposición, sino también, podríamos decir, como bien jurídico protegido $^{64}$ por la norma: los párrafos 3 y 4 del propio artículo 2, en efecto, autorizan a los Estados miembros que así lo estimen, a sancionar penalmente sólo aquellos supuestos que impliquen o puedan implicar una distorsión de la competencia en relación con la adquisición de bienes o de servicios comerciales ${ }^{65}$.

\section{LAS NACIONES UNIDAS Y LA CORRUPCIÓN EN EL SECTOR PRIVADO. LA CONVENCIÓN DE MÉRIDA DE 2003}

La Convención de las Naciones Unidas contra la Corrupción, abierta a la firma en Mérida (México) en los días 9-11 del mes de diciembre de 2003, es, sin lugar a dudas, el instrumento jurídico internacional de mayor relevancia en materia de lucha contra la corrupción. El Convenio ha sido ratificado por 148 países ${ }^{66}$ y ha entrado en vigor el 14 de Diciembre de 2005. La Convención mencionada se aprueba en respuesta a la preocupación que genera la gravedad

“de los problemas y las amenazas que plantea la corrupción para la estabilidad y seguridad de las sociedades al socavar las instituciones y los valores de la democracia, la ética y la justicia y al comprometer el desarrollo sostenible y el imperio de la ley"67.

No obstante, en el preámbulo del Convenio, se perciban con claridad los efectos negativos que la corrupción produce, es de destacar la ausencia de una definición del fenómeno. El silencio del texto legislativo sobre este punto no es casual, sino que

64 De distinta opinión FERRÉ OLIVÉ, J.C., "Corrupción en el sector privado”, en AA.VV., Corrupción en el sector privado(...) cit., p. 26 y MUSCO E., "Politica criminale...", cit., passim. Sobre el punto observamos que, con independencia de las consideraciones respecto de la necesaria taxativitad del concepto de "libre competencia" y su idoneidad a ser considerado como bien jurídico penalmente protegido, las críticas al instrumento jurídico comunitario sobre la base de la falta de indicación del objeto jurídico del delito de corrupción privada, pueden compartirse sólo parcialmente. No parece frecuente que las entidades supranacionales, a la hora de promover la tipificación de delitos, indiquen el bien jurídico protegido por los mismos. Por otro lado la exigencia de mayor determinación a nivel supranacional del tipo penal parece implicar una mayor "injerencia" en el jus puniendi del Estado nacional, injerencia que los mismos autores mencionados, parecen juzgar de excesiva.

65 Los Países miembros que así lo estimen deberán notificar las declaraciones al Consejo en el momento de la adopción de la Decisión, estas decisiones tienen validez de cinco años a partir de 22 de julio de 2005.

66 Colombia ratificó el convenio el día 13 de septiembre de 2006. La tabla actualizada de las ratificaciones es consultable a la página http://www.unodc.org/unodc/en/treaties/CAC/signatories. html. El texto oficial del convenio en español es disponible a la página http://www.unodc.org/pdf/ crime/convention_corruption/signing/Conventions.pdf 
fue consecuencia de la imposibilidad de alcanzar un acuerdo al respecto ${ }^{68}$. A falta de una definición cierta, el método utilizado fue de carácter inductivo: la postura fue la sugerida ya desde las primeras negociaciones por la delegación de Colombia, según la cual "si no se podía llegar a un acuerdo sobre una definición suficientemente amplia, la Convención no debería incluir una definición de la corrupción, sino que debería concretar y penalizar actos de corrupción en el capítulo dedicado a la penalización" ${ }^{69}$.

En otras palabras, si no fue posible alcanzar un acuerdo sobre todo lo que es o no es corrupción, sí fue posible encajar algunos supuestos en la categoría "actos de corrupción" así que, más que detenerse en esfuerzos definitorios, se optó por

68 Durante las negociaciones que llevaron a la redacción del texto definitivo del Convenio se presentaron varias y distintas propuestas de definición del término corrupción. En la segunda sesión de negociaciones el Vicepresidente encargado de este capítulo, en consulta con las delegaciones de Azerbaiyán, China, Eslovenia y Ucrania elaboró la siguiente definición: "por corrupción se entenderá la ejecución de actos o la inducción a que se ejecuten actos que constituyan ejercicio indebido del cargo [o uso indebido de autoridad], incluidas las omisiones, con la expectativa de un beneficio, o de obtener un beneficio, prometido, ofrecido o solicitado directa o indirectamente, o tras la aceptación de un beneficio otorgado directamente, ya sea en provecho propio o en nombre de otro". La delegación de Filipinas, por su parte, propuso la formulación siguiente: "Por ‘corrupción' se entenderá la promesa, la solicitud, el ofrecimiento, la entrega o la aceptación, directa o indirectamente, de un beneficio indebido o de la posibilidad de obtener un beneficio indebido que desvirtúe el debido cumplimiento de cualquiera de las funciones o conductas que incumban al receptor del soborno, el beneficio indebido o la posibilidad de obtenerlo". Durante el tercer período de sesiones del Comité Especial se formularon varias propuestas más, incluidas las de Argelia (documento A/AC.261/L.96) y Chile (documento A/AC.261/L.117). (Cita desde el documento A/AC.261/3/Rev.1 de las Naciones Unidas). A lo largo de la sexta sesión, se adoptó la definición basada en una propuesta formulada por Botswana y el Pakistán, apoyadas por los países que preferían restringir la definición de corrupción: "Sin perjuicio de los actos de corrupción generalmente reconocidos en los distintos ordenamientos jurídicos, el término "corrupción" denotará los actos previstos en la presente Convención y tipificados como delito en su capítulo III, independientemente de que se atribuyan a un funcionario público o privado, así como cualesquiera otros actos que el Estado Parte pueda haber tipificado o definido como acto de corrupción en su derecho interno o pueda penalizar o definir de ese modo en el futuro. Nada de lo dispuesto en la presente Convención limitará las posibilidades futuras de penalizar nuevos actos de corrupción o de adoptar medidas de lucha contra tales actos". Algunos miembros del grupo de trabajo oficioso que se oponían a que se mantuviera la definición expresaron su disposición a apoyar el criterio restrictivo, según el cual el término "corrupción” se empleaba en el contexto de la futura convención únicamente. Por ejemplo, el Reino Unido de Gran Bretaña e Irlanda del Norte formuló poco después una propuesta que decía: "Sin perjuicio de la variedad de actos que puedan constituir corrupción en distintos ordenamientos, el empleo del término "corrupción” en la presente Convención se referirá a [los delitos tipificados como tal con arreglo a la presente Convención] [los actos penalizados en el capítulo III de la presente Convención] y todo otro acto corrupto que se defina como tal en el derecho de cada Estado Parte. Nada de lo dispuesto en la presente Convención limitará las posibilidades futuras de penalizar nuevos actos de corrupción o de adoptar medidas de lucha contra esos actos." (documento A/AC.261/3/Rev.4). En el quinto período de sesiones del Comité Especial, la mayoría de las delegaciones señaló que prefería suprimir este apartado, postura que, no obstante ulteriores esfuerzos, prevaleció.

69 Cfr. Documento A/AC.261/3/Rev.1. 
centrarse en la individualización de estos supuestos.

Pasando a la estructura del texto legal -que se presenta especialmente complejo respecto de los anteriormente mencionados-, la Convención de las Naciones Unidas contra la Corrupción se compone de cinco secciones ${ }^{70}$ : en la tercera de ellas, titulada "penalización", el Convenio exige o recomienda que los Estados Parte tipifiquen como delito una serie de conductas que se consideran "actos de corrupción" de esta sección, es oportuno distinguir entre tres clases de normas, según su grado de obligatoriedad para los Estados miembros ${ }^{72}$ :

1. Aquellas normas que obligan sin más a los Países miembros para que tipifiquen como delito los supuestos en ellas contenidos (caracterizadas por el incipit "Cada Estado Parte adoptará las medidas legislativas y de otra índole que sean necesarias para tipificar como delito..."). En este primer conjunto, el artículo 15 del Convenio considera obligatoria la tipificación del delito de corrupción pública, en sus vertientes tanto activa como pasiva.

70 La primera de ellas incluye las "disposiciones generales", esto es, las definiciones de los términos empleados, el ámbito de aplicación y la reiteración de la protección de la soberanía de los Estados Parte. La segunda parte es dedicada a las medidas de "prevención” de la corrupción. "Tales medidas abarcan desde arreglos institucionales, como el establecimiento de un órgano concreto de prevención de la corrupción, hasta códigos de conducta y políticas de promoción de la buena gobernanza, el imperio de la ley, la transparencia y la obligación de rendir cuentas". Por lo que respecta a la tercera parte, véase en el texto. La cuarta parte es dedicada a la cooperación internacional. En esta sección, "la Convención subraya que cada uno de los aspectos de los esfuerzos de lucha contra la corrupción (prevención, investigación, enjuiciamiento de los delincuentes, incautación y restitución de los activos objeto de apropiación indebida) requiere de la cooperación internacional. La Convención requiere formas específicas de cooperación internacional, como la asistencia judicial recíproca para la reunión y transferencia de pruebas, la extradición, y la localización, el embargo preventivo, la incautación y el decomiso del producto de la corrupción. A diferencia de lo que se establecía en tratados anteriores, la Convención también prevé la prestación de asistencia judicial recíproca en ausencia de doble incriminación, siempre que esa asistencia no implique la adopción de medidas coercitivas. Además, la Convención hace hincapié en la exploración de todas las formas posibles de promover la cooperación: "En cuestiones de cooperación internacional, cuando la doble incriminación sea un requisito, éste se considerará cumplido si la conducta constitutiva del delito respecto del cual se solicita asistencia es delito con arreglo a la legislación de ambos Estados Parte, independientemente de si las leyes del Estado Parte requerido incluyen el delito en la misma categoría o lo denominan con la misma terminología que el Estado Parte requirente" (párrafo 2 del artículo 43). La quinta parte del texto normativo es dedicada a la recuperación de activos. "La restitución de activos es una innovación muy importante y "un principio fundamental de la Convención" (artículo 51). Esta parte de la Convención contiene disposiciones concretas relativas a la forma que deberán adoptar la cooperación y la asistencia, la manera de proceder para restituir el producto de la corrupción a un Estado requirente, y cómo deben considerarse los intereses de otras víctimas o de los legítimos propietarios". (Entre comillas el texto literalmente trascrito de la Guía Legislativa para la aplicación de la Convención de las Naciones Unidas contra la Corrupción” (texto integral en lengua española consultable en la web http://www.unodc.org/pdf/crime/convention corruption/cosp/Ebook/V0653443s.pdf), pp. 2 y ss).

71 Cfr. la "Guía Legislativa para la aplicación de la Convención de las Naciones Unidas contra la Corrupción”, p. 2.

72 Para esta distinción, cfr. la "Guía Legislativa(...)”, cit., pp. 3 y 4. 
2. Aquellas normas que obligan los Estados miembros a examinar la oportunidad de penalizar las conductas en ellas descritas (caracterizadas por el íncipit "Cada Estado Parte considerará la posibilidad de adoptar" las medidas legislativas y de otra índole que sean necesarias para tipificar como delito(...)"). Pertenece a este conjunto de normas el artículo 21 que se ocupa de la tipificación de la corrupción en el sector privado ${ }^{74}$.

3. Normas que promueven la adopción de medidas de carácter facultativo (caracterizadas por el íncipit "Cada Estado Parte podrá adoptar las medidas legislativas y de otra índole que sean necesarias para tipificar como delito...."). En este sentido, el artículo 27.2 del Convenio no vincula los Estados para que tipifiquen como delito la tentativa de toda conducta precedentemente descrita, sino que simplemente lo recomienda.

Ahora bien, aclarado que la norma que nos interesa tiene, en el marco del Convenio, un grado de obligatoriedad "intermedio", antes de pasar a su análisis, es oportuno subrayar como, a lo largo de las negociaciones, la sanción de la corrupción en el sector privado estuvo al centro de un debate entre dos distintas concepciones del ilícito en cuestión. Junto con una primera propuesta avanzada por las delegaciones de Austria y de los Países Bajos que incluía lo que pasó a ser el texto definitivo de la norma, la delegación de México propuso que la corrupción en el sector privado adquiriera relevancia penal sólo en el caso en que causara un perjuicio económico para la "entidad del sector privado" en la que operaba el sujeto calificado ${ }^{75}$. Dicha concepción del ilícito -que ha sido la adoptada por algunos países-, resultó minoritaria así que el texto definitivo del artículo 21 de la Convención de Mérida establece que:

"Cada Estado Parte considerará la posibilidad de adoptar las medidas

73 La dicción, de indudable eficacia "política", parece tener un alcance jurídico, por lo menos, "dudoso". En ausencia de una bibliografía a este respecto, sugerimos una interpretación que atribuya al inciso una eficacia, de alguna forma, parecida a la de la Acción común de 1998 precedentemente citada: así las cosas, cumpliría con la obligación contenida en estos artículos aquel Estado miembro que haya sometido a debate en el órgano legislativo competente la introducción de las medidas en ellas contenidas, sin perjuicio de que este órgano formule parecer negativo a su introducción en el ordenamiento jurídico interno. Notamos, finalmente, que la conjugación al futuro del tiempo verbal (adoptará, considerará, podrá) sin ninguna determinación temporal (la Acción común asignaba a los Estados miembros un plazo de dos años computados a partir de su entrada en vigor) acrece la indeterminación de los preceptos.

74 La rúbrica de la norma, en la traducción oficial española del Convenio, es "soborno en el sector privado". El término soborno se utiliza también con respecto al artículo 15, figura delictiva sustancialmente equivalente al delito del "cohecho".

75 Cfr. documento A/A. 261/3/Rev.1 consultable a la página https://www.unodc.org/pdf/crime/ convention_corruption/ session_2/3revls.pdf en el que el precepto que sancionaba la corrupción en el sector privado es contenido en el artículo 32. Cfr. sobre el punto Militiello, V., "Corruzione fra privati e scelte di incriminazione: le incertezza del nuovo reato societario", en ACQUAROLI R. -FOFFANI L., La corruzione(...) cit., p. 367. 
legislativas y de otra índole que sean necesarias para tipificar como delito, cuando se cometan intencionalmente en el curso de actividades económicas, financieras o comerciales:

a. La promesa, el ofrecimiento o la concesión, en forma directa o indirecta, a una persona que dirija una entidad del sector privado o cumpla cualquier función en ella, de un beneficio indebido que redunde en su propio provecho o en el de otra persona, con el fin de que, faltando al deber inherente a sus funciones, actúe o se abstenga de actuar;

b. La solicitud o aceptación, en forma directa o indirecta, por una persona que dirija una entidad del sector privado o cumpla cualquier función en ella, de un beneficio indebido que redunde en su propio provecho o en el de otra persona, con el fin de que, faltando al deber inherente a sus funciones, actúe o se abstenga de actuar".

La Guía Legislativa para la aplicación de la Convención de las Naciones Unidas contra la Corrupción -que, si bien no constituye una interpretación auténtica del texto $^{76}$, si tiene un indudable valor interpretativo-, subraya los siguientes elementos del tipo:

1. El "beneficio indebido": en algunos contextos nacionales, la doctrina y la jurisprudencia han debatido ampliamente sobre la necesidad de que el beneficio o la ventaja que constituye el precio del acto o de la actuación en los delitos de cohecho, tenga que ser de naturaleza económica y material para que la conducta asuma relevancia penal. La Guía Legislativa sugiere una interpretación amplia del inciso: "beneficio indebido puede ser algo tangible o intangible, pecuniario o no pecuniario".

2. Por lo que respecta al elemento subjetivo, se subraya la necesaria conexión entre el beneficio y la conducta del destinatario que podrá o no realizarse.

Por los demás aspectos de tipo penal, la Guía es reticente. Hace falta una bibliografía completa sobre el contenido de la Convención en materia de lo establecido por el artículo 21, se dirigie nuestra atención a los elementos que caracterizan la vertiente privada de la corrupción con respecto al tradicional delito de cohecho de funcionario público, conviene apuntar lo siguiente:

1. Según lo dispuesto por la Convención de las Naciones Unidas contra la Corrupción, el pago de sobornos en el sector privado asume relevancia penal en tanto en cuanto se realice "intencionalmente en el curso de actividades económicas, financieras o comerciales". Si nulla quaestio respecto del adverbio "intencionadamente" -que limita la relevancia a las conductas dolosas-, más problemático resulta determinar el exacto alcance

76 "La Guía no tiene por finalidad ofrecer una interpretación jurídica definitiva de los artículos de la Convención. Habida cuenta de que la Guía no tiene fuerza legal, al evaluar cada requisito específico, deberá consultarse el texto de las disposiciones" (Guía..cit.p. XI). 
de la expresión "actividades económicas, financieras o comerciales". La interpretación de este inciso -con particular respecto a las actividades económicas sin fin de lucro-, sea de tipo extensivo o restrictivo, dependerá de la voluntad del legislador del Estado parte a la hora de implementar el precepto o, subsidiariamente, de la interpretación doctrinal y jurisprudencial del mismo.

2. El objeto del dolo específico es necesariamente una actuación (u omisión) que configura una "falta al deber inherente a las funciones" del sujeto público vendedor. El tipo penal "corrupción en el sector privado" configurado por la Convención de las Naciones Unidas contra la Corrupción, tan sólo prevé una sanción para la vertiente (antecedente) propia del cohecho privado: con respecto a la individualización de los "deberes", si es cierto que ubi lex non distinguit, nec nos distinguere debemus, considero que la expresión ha de ser interpretada en sentido amplio, incluido, aparte de deberes que descienden de leyes o reglamentos, toda violación de obligaciones contractuales, reglas contenidas en códigos éticos o incluso de simples instrucciones. Finalmente, los deberes a los que la norma hace referencia son aquellos que guardan algún tipo de relación con la función del sujetovendedor en una "entidad del sector privado". En este caso, también parece preferible una interpretación amplia, sin limitar el alcance de la norma a los supuestos realizados por sujetos que tienen una relación de tipo laboral con una entidad privada e incluyendo las relaciones de agencia, abogado-cliente y demás. Por lo que respecta a la dicción "entidad en el sector privado", no parece casual la omisión de toda referencia a las personas jurídicas.

3. El beneficio tiene que ser "indebido": se requiere que la ventaja no sea, de alguna forma, debida, quedando así fuera del alcance de la norma todo tipo de ventaja considerada lícita por alguna fuente normativa. De especial complejidad es el caso de aquellos beneficios (económicos o no) considerados socialmente "lícitos" o, de alguna forma, asimilables a "regalos de cortesía".

\section{LOS INSTRUMENTOS JURÍDICOS INTERNACIONALES Y EL DILEMA DE LA TIPIFICACIÓN DE LA CORRUPCIÓN ENTRE PARTICULARES}

Analizados uno por uno los distintos instrumentos jurídicos internacionales que tienen normas en materia de tipificación del delito de corrupción entre particulares, puede observarse que un país que hipotéticamente se haya comprometido a cumplir con todos ellos (como, por ejemplo, España) tendrá las ideas claras respecto de algunos elementos del tipo, mientras que tendrá cierto margen de discreción respecto de otros. 
En particular, los convenios analizados parecen seguir la misma línea respecto de los términos en los cuales ha de recogerse en la ley penal la conducta típica (véase Anexo I): como se ha observado, la misma se presenta como idéntica a la que conforma el tradicional delito de cohecho. Por un lado, un sujeto (cualquiera) ofrece, da o promete (o término equivalente) y, por otro, una persona vinculada, de alguna manera, con una entidad del sector privado, solicita, recibe o acepta una promesa ${ }^{77}$.

Pocas dudas existen también respecto del objeto material de la conducta (véase Anexo II): lo ofrecido, solicitado, recibido, entregado (...) puede ser algo material, inmaterial, económicamente evaluable o no evaluable: es suficiente que se trate de una ventaja (término que equivale a beneficio) que redunde en provecho de quien la recibe o acepta o solicita o en el de otra persona ${ }^{78}$.

Respecto de los sujetos activos de la vertiente pasiva del delito (Anexo III), ya se ha aclarado la postura de cada herramienta jurídica internacional, de tal manera que conviene aquí remitir a lo dicho. Reténgase simplemente que todos los textos convencionales considerados obligan a tipificar determinadas conductas como delito, sin vincular al Estado miembro para que adopte un determinado nomen iuris. De ahí que es evidente que el abanico de sujetos activos del delito de corrupción pasiva entre particulares será inversamente proporcional a la amplitud subjetiva del delito de cohecho público ${ }^{79}$ : aquel país que considere de forma más amplia la noción de "funcionario público", sancionará como cohecho público supuestos que, en otro país, se rotularán "cohecho entre particulares". Esta diferencia, por sí sola, no bastará para alegar incumplimiento de las obligaciones contenidas en los instrumentos jurídicos internacionales considerados.

Además de lo anterior, la exacta determinación de los sujetos activos del delito de cohecho pasivo se verá también condicionada por la acotación del objeto de tutela del delito de corrupción entre particulares. A este respecto, los instrumentos jurídicos internacionales considerados resultan reticentes, mientras que los respectivos reportes explicativos, guías legislativas o preámbulos son sumamente vagos (Anexo IV). Una vez aceptada la evidente insuficiencia del apunte contenido en la Guía Legislativa de la Convención de las Naciones Unidas contra la corrupción (ya que la

77 La única duda al respecto, podría derivar de la ausencia de mención por parte de la Convención de las Naciones Unidas contra la corrupción de la conducta de "recibir" del sujeto calificado. Dicha omisión, de todas maneras, puede superarse fácilmente en vía interpretativa ya que parece evidente que quien recibe, implícita o explícitamente, antes acepta.

78 El texto de la Convención de Derecho penal del Consejo de Europa nada dice respecto de la naturaleza de la ventaja. Es preciso acudir al Explanatory Report (Párrafo 37) en el que se lee que "la ventaja indebida normalmente es de naturaleza económica pero podrá ser también de naturaleza no material". Lo mismo acontece, como ya hemos visto, respecto de la Convención de las Naciones Unidas contra la Corrupción cuyas Guías Legislativas contienen una aclaración en el mismo sentido. Más explícito es el texto de la decisión marco en el que se afirma claramente que la ventaja podrá ser "de cualquier naturaleza".

79 Piénsese, por ejemplo, en los artículos 357 y 358 del Código penal italiano. 
honestidad e integridad de la actividad empresarial difícilmente pueden ser tutelados por el derecho penal sin quebrantar la idea de esta rama del ordenamiento como ultima ratio), de lo dicho hasta ahora, parecería que las posibilidades de los países miembros a la hora de tipificar el delito de cohecho entre particulares oscilan entre el modelo que parece preferir la Convención de Derecho Penal del Consejo de Europa y aquello claramente elegido por la Decisión marco de la Unión Europea del año 2003.

El Explanatory Report anexo al primero de los dos textos mencionados, hace especial hincapié en los conceptos de lealtad y confianza ${ }^{80}$. De acuerdo con la lectura más obvia, ello parecería sugerir que, para cumplir con la obligación contenida en el texto legal, es suficiente sancionar aquellos supuestos de los cuales deriva un menoscabo para la confianza del empresario hacia el trabajador corrupto. El venir menos de la lealtad del empleado hacia su empleador sería así condición suficiente para apreciar el delito completo de todos sus elementos. Una vez acogido este modelo, es probable que el empresario (los socios) y quizás también los administradores permanezcan lógicamente fuera del abanico de sujetos activos de cohecho pasivo ya que la víctima del delito difícilmente puede ser a la vez su autor.

Más precisa resulta a este respecto la Decisión marco: la referencia a la competencia es evidente y el artículo 2.3 puntualiza que

“todo Estado miembro podrá declarar que limitará el ámbito de aplicación (...) a aquellos actos que impliquen o puedan implicar una distorsión de la competencia en relación con la adquisición de bienes o de servicios comerciales".

$\mathrm{Si}$, por un lado, cabe preguntarse qué otro ámbito de aplicación puede tener el delito (y sobre todo si los compiladores de este instrumento jurídico tienen en la mente un alcance más amplio que no explicitan), por otro, parece lícito esperarse que aquellos países que convengan que el cohecho entre particulares merece ser incluidos en los códigos penales internos en tanto suponga una distorsión de la competencia, incluirán en el abanico de sujetos activos de la vertiente pasiva del delito tanto administradores como socios de la entidad privada que, es evidente, no pueden legítimamente disponer del bien jurídico protegido.

Para terminar este análisis, parece oportuno apuntar que, en materia de características tanto cuantitativas como cualitativas de las penas, la aportación de los distintos instrumentos internacionales considerados es distinta (Anexo VI). En materia de cohecho entre particulares, la Convención de las Naciones Unidas contra la corrupción deja mucha discrecionalidad al Estado miembro a la hora de cuantificar la sanción: la pena que debe imponerse ha de ser simplemente proporcionada a la gravedad del ilícito. La Convención de Derecho Penal del Consejo de Europa, por su parte, obliga a prever sanciones que puedan dar lugar a extradición. Distinta es la postura adoptada por la Decisión marco del año 2003 que detalla mucho más la pena que debe imponerse.

80 No obstante, como se ha dicho, también se hace mención de la lealtad competencial. 
Sobre esta particular, conviene ahora destacar que, como se ha observado en doctrina, la determinación a nivel internacional de las penas mínimas y/o máximas que debe imponerse a un ilícito que debe tipificarse en distintos países, puede tener ciertos inconvenientes de cara a la coherencia interna de los textos legales. El esfuerzo del legislador internacional es ciertamente ímprobo: por un lado, corre el riesgo de que la pretendida armonización sea de facto anulada por previsiones de sanciones insignificantes a nivel nacional; por otro, cuando procura precisar demasiado, se arriesga a incidir profundamente sobre el código penal nacional que, no se olvide, es un conjunto de normas que tiene que mantener cierta coherencia que ha de pivotar, in primis, sobre la idea de proporcionalidad ${ }^{81}$. Como colofón, no sobra recordar que, incluso para aquellos países que hayan ratificado la sola Convención de las Naciones Unidas contra la Corrupción, de acuerdo con los principios generales que guían la interpretación de todo tratado internacional, las normas en ella contenidas (incluidas las que obligan a sancionar de forma proporcional y disuasoria) han de ser implementadas según buena fe y privilegiar, en todo caso, la exégesis más útil ${ }^{82}$.

Siempre en materia de consecuencias jurídicas del ilícito, la tipificación del delito de corrupción entre particulares ha sido terreno fértil para experimentar sanciones de tipo penal a conminarse a las personas jurídicas ${ }^{83}$. Sobre este punto (véase Anexo VI), conviene aquí insistir en el hecho que ni la Convención de las Naciones Unidas contra la corrupción ni la Convención de Derecho penal del Consejo de Europa obligan de ninguna manera a sancionar de forma penal a las personas morales responsables de cohecho privado. Tampoco la Decisión marco del año 2003 exige que la sanción que debe imponerse a la persona jurídica sea de carácter penal pero requiere que el legislador nacional elija entre sanciones penales o administrativas, descartando la suficiencia de la vía civil (que, en cambio, es dejada abierta por los dos demás instrumentos considerados).

Siempre en el marco de las posibles sanciones que han de imponerse a las personas jurídicas (Anexo VII), destaca ciertamente la relevancia atribuida a la culpa in vigilando por parte de la Convención penal del Consejo de Europa y de la Decisión marco.

81 Sobre este punto, véase Nieto Martín, A., "La armonización del derecho penal(...)", cit., p. 3.

82 Véase la sentencia CIJ en el asunto sobre Diferencia territorial entre Libia y Chad, Recueil 1994 , pp. 21-22 en la que se lee que "según el derecho internacional consuetudinario, que ha encontrado su expresión en el artículo 31 de la Convención de Viena de 1969 sobre Derecho de los Tratados, un tratado debe ser interpretado de buen fe conforme al sentido ordinario a atribuir a sus términos en su contexto y a la luz de su objeto y fin. La interpretación debe estar fundada ante todo en el texto del tratado mismo". El caso, así como otros pronunciamientos en el mismo sentido, se ha citado literalmente de Díez de Velasco, M., Instituciones de derecho internacional público, XIV Edición, Tecnos, Madrid, 2003, p. 183. En el mismo sentido, véase CONFORTI, B., Diritto internazionale, Editoriale Scientifica, Napoli, 2002, pp. 105 y ss.

83 Ésta, por ejemplo, es la elección de la Ley Orgánica 5/2010 española. 


\section{A MODO DE CONCLUSIÓN: EL ESTUDIO DE LOS INSTRUMENTOS INTERNACIONALES COMO PREMISA NECESARIA PARA LA TIPIFICACIÓN DE LA CORRUPCIÓN ENTRE PARTICULARES}

En las páginas anteriores, me he limitado a proporcionar un conjunto de observaciones de carácter esencialmente descriptivo acerca de las obligaciones de tipificación de conductas de soborno entre particulares contenidas en los principales instrumentos jurídicos internacionales. Ello, en un dúplice entendimiento: en primer lugar, cualquier Estado que haya ratificado o resulte parte de alguna o de todas las herramientas supranacionales consideradas, deberá medirse con la compleja problemática subyacente a la tipificación de un delito de corrupción entre privados. Lo mismo deberá advertírsele a cualquier país que pretenda convertirse en parte de uno de los convenios o bien que se incorpore a la Unión Europea. En segundo lugar, debe volver a hacerse hincapié en que, si se comparte que la problemática que subyace a la globalización requiere, entre otras cosas, una armonización de los distintos derechos penales internos, deberá también convenirse que las indicaciones que proceden de los instrumentos internacionales analizados se convierten en auténticas guías maestras para los legisladores nacionales, incluso al margen de la existencia de obligaciones supranacionales.

Estas últimas observaciones vuelven a plantear el problema del cual habíamos empezado: ¿Más allá de publicitar la firma y ratificación de este o de aquel convenio, se preocupan los países miembros de implementarlos correctamente? A este respecto, digamos desde ya que sorprende que tanto la doctrina como las principales organizaciones internacionales, por lo general, hayan dejado en un segundo plano el análisis del grado de cumplimiento de las obligaciones contenidas en las herramientas internacionales de lucha contra la corrupción.

Por las razones antes aludidas, resulta menos sorprendente (aunque no menos criticable) la actitud de los países miembros de los tratados. En materia de tipificación de la corrupción entre particulares, el caso del Reino de España es paradigmático: no obstante las repetidas proclamas del Gobierno y la oposición acerca del necesidad de impulsar con dureza la lucha contra la corrupción, hubo que esperar al año 2010 para ver aprobada la reforma del delito de cohecho y la introducción de un delito de corrupción en el sector privado (el primer anteproyecto en este sentido se presentó a finales del año $2006^{84}$ ). Sobre la bondad de las elecciones del legislador español de 2010, conviene aquí suspender el juicio. Valga ahora recordar que el Reino de España estaba obligado a introducir un delito de corrupción entre particulares desde el año 1998 y que el primer plazo útil para hacerlo venció en el año $2000^{85}$. Y reténgase también que, mientras el legislador español seguía sin cumplir con las obligaciones

84 Boletín oficial de las Cortes Generales No. 119-1 (VIII legislatora) de 15 de enero de 2007.

85 Véase supra a propósito de la Acción Común del año 1998. 
contenidas en la Acción Común del año 1998 y en la Decisión marco del año 2003, el Gobierno de España, respaldado por el Parlamento (es decir, el propio legislador) ratificaba tratados que obligaban a tipificar (o a considerar la posibilidad de tipificar) el delito de corrupción privada (como la Convención de las Naciones Unidas contra la corrupción ${ }^{86}$ y la Convención de Derecho penal contra la corrupción del Consejo de Europa ${ }^{87}$ ). En este mismo sentido, debe llamar la atención la relación cronológica entre la reforma del Código penal español y la publicación del primer documento que puso de manifiesto la inconsistencia de la legislación española en la materia y el contenido de los principales instrumentos jurídicos internacionales. Y, en efecto, el día 15 de mayo de 2009, el Grupo de Estados contra la Corrupción (GRECO) ${ }^{88}$, en el marco de la tercera ronda de evaluaciones sobre el cumplimiento de las obligaciones contenidas en la Convención de Derecho penal del Consejo de Europa, adoptaba el "Informe de evaluación relativo a España" 89 que tenía como objeto un análisis del grado de implementación de las medidas de "incriminación" contenidas en el mencionado Convenio (entre las cuales, como hemos visto, se encuentra la tipificación de un delito de corrupción en el sector privado). La publicación del informe ha seguramente impulsado y guiado el legislador nacional que, después de más de dos lustros de incumplimiento, se ha finalmente decidido a obtemperar con las obligaciones internacionales que él mismo había libremente contraído.

Esta última observación abre la puerta al debate acerca de la importancia de la elaboración por parte de los organismos internacionales de mecanismos de seguimiento de la implementación de los convenios.

A este respecto, baste ahora observar, de cara al futuro, que ha sido recientemente aprobado por la Conferencia de Estados parte el mecanismo de seguimiento de la Convención de las Naciones Unidas contra la Corrupción ${ }^{90}$. Colombia es parte de este Convenio desde el año 2006. Y quizás que el aproximarse de la evaluación del grado de cumplimiento de los requerimientos contenidos en el mencionado Tratado no otorgue más protagonismo a un debate que, desde hace cuatro años, debería ser actual en el país. Dos son las preguntas esenciales del mismo: ¿Debe tipificarse el

86 La Convención de las Naciones Unidas contra la Corrupción ha sido ratificada por España en el día 19 de junio de 2006 (BOE de 19 de Julio de 2006, No. 171).

87 BOE No. 182 de 28 de julio de 2010, Sec. I., p. 65780. El instrumento de ratificación, por otra parte, ha sido depositado en el día 28 de abril de 2010 y el Convenio ha entrado en vigor para España en el día 1 de agosto de 2010. Para consultar la tabla de ratificaciones y firmas, véase la página Web http://conventions.coe.int/Treaty/Commun/ChercheSig.asp?NT= $173 \& \mathrm{CM}=8 \& \mathrm{DF}=08 / 08 / 2010 \& \mathrm{CL}=\mathrm{ENG}$.

88 http://www.coe.int/t/dghl/monitoring/greco/general/2.\%20Historical\%20Background_en.asp.

89 El informe puede consultarse en idioma español, francés e inglés en la página Web http://www.coe. int/t/dghl/ monitoring/greco/evaluations/round3/ReportsRound3_en.asp.

90 A la hora de elaborar el mecanismo es evidente que se tomó como referencia la ya mencionada Convención de OCDE del año 1997 ya que esencialmente se tratará de una evaluación mutua entre Estados partes. Sin poder ahora entrar en detalles por evidentes motivos de espacio, me limito a remitir el lector a la página http://www.unodc.org/unodc/en/treaties/CAC/IRG.html. 


\section{delito de cohecho entre particulares? Y, si es que sí: ¿Cómo ha de tipificarse? $\mathrm{El}$ estudio anterior pretende sentar las bases para las respuestas.}

\section{Anexo 1: Conductas típicas}

\begin{tabular}{|c|c|c|}
\hline & \multicolumn{1}{|c|}{ Cohecho Activo } & \multicolumn{1}{c|}{ Cohecho Pasivo } \\
\hline $\begin{array}{c}\text { Convención Penal del } \\
\text { Consejo de Europa }\end{array}$ & $\begin{array}{l}\text { Prometer, ofrecer u otorgar, directa } \\
\text { o indirectamente }\end{array}$ & $\begin{array}{l}\text { Solicitar o recibir, directamente o por } \\
\text { mediación de terceros, aceptar la oferta o } \\
\text { la promesa }\end{array}$ \\
\hline $\begin{array}{c}\text { Decisión Marco de la UE } \\
\text { Prometer, ofrecer o entregar } \\
\text { directamente o a través de un } \\
\text { intermediario Pedir, recibir, directamente o a través de } \\
\text { un intermediario, (...) o aceptar la promesa }\end{array}$ \\
\hline $\begin{array}{c}\text { Convención de UN contra } \\
\text { la corrupción }\end{array}$ & $\begin{array}{l}\text { La promesa, el ofrecimiento o } \\
\text { la concesión, en forma directa o } \\
\text { indirecta }\end{array}$ & $\begin{array}{l}\text { Solicitar aceptar, en forma directa o } \\
\text { indirecta }\end{array}$ \\
\hline
\end{tabular}

Anexo 2: Objeto material de la conducta

\begin{tabular}{|c|c|}
\hline $\begin{array}{c}\text { Convención Penal del } \\
\text { Consejo de Europa }\end{array}$ & Cualquiera ventaja indebida (...) para sí misma o para cualquier otra persona \\
\hline Decisión Marco de la UE & Una ventaja indebida de cualquier naturaleza para dicha persona o para un tercero \\
\hline $\begin{array}{c}\text { Convención de las UN } \\
\text { contra la corrupción }\end{array}$ & $\begin{array}{l}\text { "El delito debe abarcar los casos en que lo que se ofrece no es un regalo o algo } \\
\text { tangible. Así pues, un beneficio indebido puede ser algo tangible o intangible o no } \\
\text { pecuniario" 91 }\end{array}$ \\
\hline
\end{tabular}

Anexo 3: Sujetos activos de corrupción pasiva

\begin{tabular}{|c|l|}
\hline $\begin{array}{c}\text { Convención Penal del } \\
\text { Consejo de Europa }\end{array}$ & $\begin{array}{l}\text { "Persona que dirija o trabaje en cualquier calidad para una entidad del sector } \\
\text { privado" }\end{array}$ \\
\hline $\begin{array}{c}\text { Decisión marco } \\
\text { de la UE }\end{array}$ & $\begin{array}{l}\text { "Una persona que desempene funciones directivas o laborales de cualquier } \\
\text { tipo para una entidad del sector privado" }\end{array}$ \\
\hline $\begin{array}{c}\text { Convención de las UN contra } \\
\text { la corrupción }\end{array}$ & $\begin{array}{l}\text { "Una persona que dirija una entidad del sector privado o cumpla cualquier } \\
\text { función en ella" }\end{array}$ \\
\hline
\end{tabular}

$91 \quad$ Véase Guías Legislativas, p. 114 


\section{Anexo 4: La lesividad de la corrupción en el sector privado}

\begin{tabular}{|c|c|}
\hline $\begin{array}{c}\text { Convención de Derecho Penal } \\
\text { del Consejo de Europa }\end{array}$ & $\begin{array}{l}\text { "Los actos de corrupción en el sector privado representan una vulneración de } \\
\text { los valores de lealtad y confianza, valores necesarios para el mantenimientos } \\
\text { de las relaciones sociales y económicas" }\end{array}$ \\
\hline Decisión marco de la UE & $\begin{array}{l}\text { "Los Estados miembros conceden una importancia especial a la lucha contra } \\
\text { la corrupción en el sector público como en el privado, por estimar que en } \\
\text { ambos sectores, constituye una amenaza para el Estado de Derecho, al } \\
\text { tiempo que distorsiona la competencia respecto de la adquisición de bienes o } \\
\text { servicios comerciales e impide un desarrollo económico sólido" }\end{array}$ \\
\hline $\begin{array}{c}\text { Convención de las Naciones } \\
\text { Unidas contra la corrupción }\end{array}$ & $\begin{array}{l}\text { "El artículo 21 se destaca la importancia de exigir integridad y honestidad en } \\
\text { las actividades económicas, financieras o comerciales"92 }\end{array}$ \\
\hline
\end{tabular}

\section{Anexo 5: Penas}

\begin{tabular}{|c|l|}
\hline $\begin{array}{c}\text { Convención de Derecho Penal } \\
\text { del Consejo de Europa }\end{array}$ & $\begin{array}{l}\text { "Sanciones y medidas efectivas, proporcionadas y disuasorias que incluyan, } \\
\text { cuando sean cometidas por personas física, sanciones privativas de libertad } \\
\text { que puedan dar lugar a extradición"93 }\end{array}$ \\
\hline $\begin{array}{c}\text { Convención de UN contra la } \\
\text { corrupción }\end{array}$ & $\begin{array}{l}\text { "cada Estado parte penalizará la comisión de los delitos tipificados con } \\
\text { arreglo a la presente Convención con sanciones que tengan en cuenta la } \\
\text { gravedad de esos delitos"94 }\end{array}$ \\
\hline Decisión marco de la UE & $\begin{array}{l}\text { "Los actos de corrupción privada tanto activa como pasiva "sean punibles } \\
\text { con sanciones privativas de libertad de una duración máxima de al menos de } \\
\text { uno a tres años". A una persona física que haya sido condenada por cohecho } \\
\text { entre particulares" en relación con alguna actividad profesional en el sector } \\
\text { privado, al menos en los casos en que haya ocupado un puesto destacado } \\
\text { en la empresa dentro del ramo de actividad de que se trate, se le pueda } \\
\text { prohibir temporalmente el ejercicio de esa actividad profesional o de una } \\
\text { actividad comparable en un puesto o función similares, cuando los hechos } \\
\text { comprobados den motivos para pensar que existe un claro riesgo de que } \\
\text { abuse de su posición cargo mediante actos de corrupción activa o pasiva". }\end{array}$ \\
\hline
\end{tabular}

Anexo 6: Responsabilidad de las personas jurídicas

\begin{tabular}{|c|c|}
\hline $\begin{array}{c}\text { Convención de Derecho Penal } \\
\text { del Consejo de Europa }\end{array}$ & $\begin{array}{l}\text { "Las personas jurídicas sean objeto de sanciones eficaces, proporcionadas } \\
\text { y disuasorias de naturaleza penal o no penal, incluidas las sanciones } \\
\text { pecuniarias"95 }\end{array}$ \\
\hline Decisión marco de la UE & $\begin{array}{l}\text { "Los Estados miembros tomarán las medidas necesarias para asegurar } \\
\text { que las personas jurídicas consideradas (...) puedan ser castigadas con } \\
\text { sanciones efectivas, proporcionadas y disuasorias, que incluirán multas de } \\
\text { carácter panel o administrativo". }\end{array}$ \\
\hline $\begin{array}{c}\text { Convención de las UN contra } \\
\text { la corrupción }\end{array}$ & $\begin{array}{l}\text { "Con sujeción a los principios jurídicos del Estado parte, la responsabilidad } \\
\text { de las personas jurídicas podrá ser de índole penal, civil o administrativa"96. }\end{array}$ \\
\hline
\end{tabular}

92 Véase Guía Legislativa, p. 114.

93 Artículo 19.

94 Artículo 30.

95 Artículo 19.

96 Artículo 26. 


\section{Anexo 7: Sanciones para las personas jurídicas}

\begin{tabular}{|c|c|}
\hline $\begin{array}{c}\text { Convención de } \\
\text { Derecho Penal del } \\
\text { Consejo de Europa }\end{array}$ & $\begin{array}{l}\text { "Cada parte adoptará las medidas legislativas y de otra índole que sean necesarias para } \\
\text { garantizar que se pueda hacer responsables a las personas jurídicas de los delitos de } \\
\text { corrupción activa (...), cuando sean cometidos en beneficio de aquéllas por una persona } \\
\text { física, actuando individualmente o como miembro de un órgano de la persona jurídica, } \\
\text { que ejerza un poder directivo dentro de ésta, sobre la base de: } \\
\text { 1.un poder de representación de la persona jurídica; o } \\
\text { 2. una autoridad para adoptar decisiones en nombre de la persona jurídica; } \\
\text { 3. o una autoridad para ejercer control en el seno de la persona jurídica; } \\
\text { 4. así como de la participación de esa persona física en calidad de cómplice o de } \\
\text { instigador } \\
\text { 5. en la comisión de los delitos anteriormente mencionados. } \\
\text { 2. Aparte de los casos ya previstos en el apartado } 1 \text {, cada Parte adoptará las medidas } \\
\text { necesarias para garantizar que se pueda hacer responsable a una persona jurídica cuando } \\
\text { la falta de vigilancia o de control por parte de una de las personas físicas a que se refiere } \\
\text { el apartado } 1 \text { haya hecho posible la comisión, por parte de una persona física sometida } \\
\text { a su autoridad, de los delitos mencionados en el apartado } 1 \text { en el beneficio de dicha } \\
\text { persona jurídica. } \\
\text { 3. La responsabilidad de la persona jurídica en virtud de los apartados } 1 \text { y } 2 \text { no excluye la } \\
\text { acción penal contra las personas físicas autoras, instigadoras o cómplices de los delitos } \\
\text { mencionados en el apartado } 1 \text { " } 97 \text {. }\end{array}$ \\
\hline $\begin{array}{l}\text { Decisión marco de la } \\
\text { UE }\end{array}$ & $\begin{array}{l}\text { "Los Estados miembros tomarán las medidas necesarias para asegurar que las personas } \\
\text { jurídicas consideradas responsables en virtud del apartado } 1 \text { del artículo } 5^{98} \text { puedan ser } \\
\text { castigadas con sanciones efectivas, proporcionadas y disuasorias, que incluirán multas } \\
\text { de carácter penal o administrativo, y que podrán incluir otras sanciones, tales como: } \\
\text { a)exclusión del disfrute de ventajas o ayudas públicas } \\
\text { b) inhabilitación temporal o permanente para desempeñar actividades comerciales, c) } \\
\text { vigilancia judicial, o } \\
\text { d) medida judicial de disolución. } \\
\text { 2.Los Estados miembros tomarán las medidas necesarias para asegurar que las personas } \\
\text { jurídicas consideradas responsables en virtud del apartado } 2 \text { del artículo } 5^{99} \text { puedan ser } \\
\text { castigadas con sanciones o medidas efectivas, proporcionadas y disuasorias. }\end{array}$ \\
\hline $\begin{array}{l}\text { Convención de las UN } \\
\text { contra la Corrupción }\end{array}$ & $\begin{array}{l}\text { La responsabilidad sin perjuicio de la responsabilidad penal que incumba a las personas } \\
\text { naturales que hayan cometido los delitos. } \\
\text { Cada Estado parte velará en particular por que se impongan sanciones penales o no } \\
\text { penales eficaces, proporcionada y disuasivas, incluidas sanciones monetarias, a las } \\
\text { personas jurídicas consideras responsables con arreglo al presente artículo. }\end{array}$ \\
\hline
\end{tabular}

\section{Artículo 18}

98 "Los Estados miembros tomarán las medidas necesarias para asegurar que las personas jurídicas puedan ser consideradas responsables de las infracciones mencionadas en los artículos 2 y 3 cometidas en su provecho por cualquier persona que, al actuar a título individual o como parte de un órgano de la persona jurídica, ostente un cargo directivo en el seno de dicha persona jurídica basado en: a) un poder de representación de dicha persona jurídica, o b) una autoridad para tomar decisiones en nombre de dicha persona jurídica, o c) una autoridad para ejercer el control en el seno de dicha persona jurídica".

99 “(...) los Estados miembros tomarán las medidas necesarias para asegurar que pueda considerarse responsable a una persona jurídica cuando la falta de vigilancia o control por parte de una de las personas mencionadas en el apartado 1 haya hecho posible que una persona sometida a la autoridad de la persona jurídica cometa en provecho de ésta una infracción del tipo descrito en los artículos 2 y 3 ". 


\section{REFERENCIAS}

Bauman, Z., (2000) "Social Issues of Law and Order", en The British Journal of Criminology, n. 40.

Berdugo Gómez De La Torre, I., y otros, Curso de Derecho penal, parte general, de. Experiencia, Barcelona, 2010, pág. 72.

Berdugo Gómez De La Torre, I., y otros, Curso(...) cit., pág. 73.

Boe No. 182 de 28 de julio de 2010, Sec. I., pág. 65780.

Boe de 22 de junio de 2010, No. 152.

Boletín oficial de las Cortes Generales No. 119-1 (VIII legislatora) de 15 de enero de 2007.

Código penal italiano.

Cotler, I., (2002) "Globalization, Human Security, and the Role of International Criminal Law", en AA.VV., The Changing Face of International Criminal Law. Selected Papers, Canadian Department of Justice.

De La Cuesta Arzamendi, J. L. -Blanco Cordero, I., "La criminalización de la corrupción en el sector privado: ¿Asignatura pendiente del derecho penal español?".

Conforti, B., (2002) Diritto internazionale, Editoriale Scientifica, Napoli.

Delmas-Marty, M., (2009) “Objetivos y metodología”, en Aa. Vv., Delmas Marty, M. -Pieth, M. -Sieber, U. (Dirs.), Los Caminos de la armonización penal, España: Tirant lo blanch.

Diario Oficial de las Comunidades Europeas L 192/54 de 31 de julio de 2003, consultable la página http://eur-lex.europa.eu/LexUriServ/LexUriServ.do?uri= OJ:L:2003:192:0054:0056:ES:PDF.

DiarioOficial,n.L.358de31 dediciembrede 1998. Textoconsultablealapáginahttp://eurlex.europa.eu/LexUriServ/LexUriServ.do?uri=CELEX:31998F0742:ES:HTML

Díez De Velasco, M., (2003) Instituciones de derecho internacional público, España: Tecnos, Madrid.

Diez Ripollés, J. L. (Coord.), (2002) La ciencia del derecho penal ante el nuevo siglo: libro homenaje al profesor doctor don José Cerezo Mir, España: Tecnos.

Doce L 192 de 31.de julio de 2003.

Doce L 358 de 31 de diciembre de 1998.

Dupuis M. B., (1995) La corruzione, Cedam, Padua.

Ferré Olivé, J.C., (2003) “Corrupción en el sector privado", en AA.VV., Corrupción en el sector privado, Material z konferencji w Krakowie, 10-13, Lipca, Wydawnichtwo Naukowe

Fabián Caparrós, E. A., (2007) La corrupción (...)cit., pp. 30 y ss. 
Fabián Caparrós, E.A., (2002) La corrupción de agente público extranjero e internacional, Ratio Legis, Salamanca.

Forti, G., (2003) "Il volto di Medusa: la tangente come prezzo della paura", en Forti, G., (Dir.) Il prezzo della tangente, Vita e Pensiero, Milano.

Huber, B., (2003) "LA lucha contra la corrupción desde una perspectiva supranacional", en Revista Penal.

La Convención de las Naciones Unidas contra la Corrupción ha sido ratificada por España en el día 19 de junio de 2006 (BOE de 19 de Julio de 2006, No. 171).

Lora E. -Panizza U., (2002) "Globalización y reformas estructurales en América latina: lo que funcionó y lo que no”, en Revista Asturiana de Economía, No. 24.

Manfroni, C. A., (1998) Soborno Transnacional, Abeledo-Perrot, Buenos Aires, passim y, en particular.

Mirri M.B., (1987) "I delitti di corruzione: disciplina positiva e prospettive di riforma", en La Giustizia Penale.

Musco E., "Politica criminale in materia di corruzione privata", en AA.VV., Corrupción en el sector privado...cit., loc. cit.; Ferrè Olivè, J. C., ob. cit., loc. cit.)

Mueller G. O. W., (2001) “Transnational Crime: Definitions and Concepts”, en Williams P. -Vlassis D., Combating Transnational Crime: Concepts, Activities, and Responses, Routledge,

Nieto Martín, A., (2009) “¿Americanización o europeización del Derecho penal económico?”, en Aa. Vv., Delmas-Marty, M. -Pieth, M. -Sieber, U. (Dirs.), Los Caminos de la armonización penal, Tirant lo blanch, Valencia, 2009, pp. 435 y ss.; Pieth, M., "La armonización del Derecho penal: la prevención de la corrupción como caso de estudio", en AA. Vv., Delmas-Marty, M. -Pieth, M. -Sieber, U. (DIRS.), Los Caminos de la armonización penal, Tirant lo blanch, Valencia.

Nieto Martín, A., (2005) "Fundamentos constitucionales del sistema europeo de derecho penal", en Revista General de Derecho Penal, No. 3 Mayo, passim (consultado en versión electrónica).

Nieto Martín, A., (2010) "La armonización del derecho penal ante el tratado de Lisboa y el programa de Estocolmo", en Revista General de Derecho Penal, n. 13 (versión electrónica).

Nieto Martín, A., “La armonización del derecho penal(...)”, cit., p. 3.

Olaizola Nogales, (1999) I., El delito de Cohecho, España: Tirant lo Blanch.

Palomo De Arco, A., "El delito de corrupción en el sector privado como ejemplo de incidencia del derecho comunitario en el derecho penal de los Estados miembros", en AA.VV., La corrupción en el sector privado.g

Roberts, J. V. -Stalans, L. J. -Indermaur, D. Hough, M., (2002) Penal Populism and Public Opinion, Oxford University Press, USA,; Pratt, J., Penal populism, Routledge, 2007. 
Rodríguez García, N. -Fabián Caparrós, E. A. (Coords.), (2004) La corrupción en un mundo globalizado: análisis interdisciplinar, Ratio Legis, Salamanca.

Rodríguez Puerta, M.J., (1999) El delito de cohecho: problemática jurídico-penal del soborno de funcionarios, Aranzadi, Pamplona, , pp. 66 y ss.; sostienen que el bien jurídico protegido por los delitos de cohecho es el "correcto funcionamiento de la Administración Pública".

Segreto, A. -De Luca, G., (1995) I delitti dei pubblici ufficiali contro la pubblica amministrazione, II ed., Giuffrè, Milano, , pp. 453 y ss.; VASSALLI, G., "Corruzione propria e corruzione impropria", en La Giustizia Penale, 1979, p. 326; BRICOLA, F., (1968) "Tutela penale della Pubblica amministrazione e principi costituzionali”, en Temi.

Seminara S., "sin título", en Acquaroli R. -Foffani L., (a cura di), (2002) La Corruzione tra privati, esperienze comparatistiche e prospettive di reforma, atti del convegno, Jesi (AN), 12-13 aprile, Giuffrè.

Sentencia TJCE C-105/03 en materia de Decisión marco 2001/220/JAI del Consejo, de 15 de marzo de 2001, relativa al estatuto de la víctima en el proceso penal. cfr. Castillo García, J.F., La comunitarización del tercer pilar: un paso necesario para la consolidación del espacio penal europeo, en Revista General de Derecho europeo, n. 11, 2006, en IUSTEL RI §794239, pp. 5 y ss.

Silva Sánchez, J. M., (2006). La expansión del Derecho penal, Julio César Faira, Montevideo, Buenos Aires.

Silva Sánchez, J., La Expansión. Nieto Martín, A., "Posibilidades y límites de la armonización del Derecho Penal nacional tras Comisión v. Consejo (comentario a la STJCE, asunto C-176/03, de 13-9-2005)", en Revista española de derecho europeo, n. 17, 2006, p. 198 y ss; GRASSO, G., "La formación de un Derecho penal de la Unión Europea,” en Revista del poder judicial, n. 52, 1998, p. 179.

Stiglitz, J. E., El malestar de la globalización, Taurus, Madrid, 2003, p. 11). Para una conceptualización de la globalización relacionada con el derecho penal, véase Quintero Olivares, G., "El Derecho Penal ante la globalización”, en Aa.Vv., Zúñiga Rodríguez, L. -Méndez Rodríguez, C. -Diego Díaz-Santos, M. R. El Derecho Penal ante la Globalización, Colex, Madrid, 2002, pp. 11 y ss.

Tagliarini, F., (1973) Il concetto di Pubblica Amministrazione nel codice penale, Giuffrè, Milano;

Valeije Álvarez, I., (1995) El tratamiento penal de la corrupción del funcionario: el delito de cohecho, Editoriales de Derecho Reunidas, Madrid.

Vogel, J., (2002) "Estado y tendencias de la armonización del Derecho penal material en la Unión Europea”, en Revista Penal. 